\title{
0 que Fazem os Conselhos e Quando o Fazem? Padrões Decisórios e o Debate dos Efeitos das Instituições Participativas*
}

\author{
Adrian Gurza Lavalle ${ }^{1}$ \\ Jessica Voigt ${ }^{1}$ \\ Lizandra Serafim ${ }^{2}$ \\ ${ }^{1}$ Unversidade de São Paulo (USP), São Paulo, SP, Brasil. E-mail para contato: \\ gurzalavalleadrian@gmail.com \\ 'Universidade Federal da Paraíba (UFPB), João Pessoa, PB, Brasil.
}

\section{INTRODUÇÃO}

W os anos da pós-transição, a regulação das disposições constitucionais mandatando a participação em determinados setores de políticas públicas e a ampliação do escopo de sua implementação a um conjunto maior de áreas acabaram por definir a participação como um traço do Estado no Brasil, atingindo patamares de institucionalização ímpares na história do país e em outras democracias. Algumas cifras bastam para esboçar a envergadura dessa institucionalização: existem aproximadamente 30 mil conselhos gestores de políticas públicas (doravante conselhos) nos 5.570 municípios do Brasil, e, por conseguinte, várias dezenas de milhares de conselheiros da sociedade civil participando na definição e na supervisão de políticas públicas (Gurza Lavalle e Barone, 2015; IBGE-Munic, 2009; Teixeira, 2014).

\footnotetext{
* Este artigo é produto do projeto "Desigualdade Política e Representação Extraparlamentar", realizado pelo Centro de Estudos da Metrópole/Centro de Pesquisa, Inovação e Difusão (CEM-Cepid) e financiado pela Fundação de Amparo à Pesquisa do Estado de São Paulo (Fapesp), processo n-2013/07616-7. As opiniões, hipóteses e conclusões ou recomendações expressas são de responsabilidade dos autores e não necessariamente refletem a visão da Fapesp. O artigo dá continuidade à investigação das características da governança participativa local no Brasil, iniciada no projeto "Urban Chances - City Growth and the Sustainability Challenge. Comparing Fast Growing Cities in Growing Economies", mediante financiamento do Seventh Framework Programme - União Europeia.
}

DADOS - Revista de Ciências Sociais, Rio de Janeiro, vol. 59, no3, 2016, pp. 609 a 650. 
Às cifras sobre os conselhos seria possível acrescer as 82 conferências nacionais realizadas de 2003 a 2011, precedidas por conferências municipais e estaduais preparatórias que mobilizam de dezenas a centenas de milhares de participantes cada (Souza et al., 2013), ou a multiplicação de audiências públicas - mandatórias quando da realização de investimentos de grande porte ou com consequências potencialmente danosas para o meio ambiente, o patrimônio ou a vida de uma comunidade -, ou processos participativos na formulação de planos diretores (Santos Junior e Montandon, 2011). Já em relação a experiências de orçamento participativo (OP), Fedozzi e Lima (2013) estimam que, em 2013, havia 305 iniciativas em curso no Brasil. Em todos os casos, com exceção do OP, trata-se de canais de participação com ampla cobertura territorial.

Em face de tamanha expansão e institucionalização, no campo de estudos da participação adquiriu ressonância a ideia de olhar para as instituições de participação em sua totalidade, e não apenas para uma instância participativa específica - sendo esta conselho, conferência ou OP - ou para um setor de políticas em particular. A literatura deslocou os termos do debate ao promover uma nova agenda de pesquisa não mais sobre participação, mas sim, emblematicamente, sobre instituições participativas (IPs) e sua efetividade (Avritzer, 2009; Pires, 2010, 2011). De forma específica, em relação aos conselhos com mais presença no plano municipal, como os de saúde, de direitos da criança e do adolescente, e de assistência social, a agenda centrada na efetividade das IPs reconhece o acúmulo de conhecimento produzido pela literatura nas últimas duas décadas e parte daí. Contudo, como esse conhecimento descansou em especial em estudos de caso, atenta-se para uma lacuna que precisa ser preenchida: ainda se sabe pouco sobre os efeitos que os conselhos produzem em conjunto, e os resultados descritos pela literatura com base em estudos de caso oferecem condições limitadas para sua generalização (Pires e Vaz, 2010a) ${ }^{1}$.

Sanar a lacuna apontada pela literatura quanto ao conhecimento disponível acerca da efetividade das IPs impõe desafios analíticos e metodológicos, a começar pela adoção de unidades de observação e de agregação adequadas para permitir o exame das IPs em níveis empíricos mais gerais e em níveis analíticos mais abstratos em vez de examinar um conselho específico e os processos políticos e de funcionamento colegiado atinentes a ele (Pires, 2010). A escolha de outras unidades de observação e de agregação implica também o emprego de modalidades de formalização e de quantificação com o intuito de sistematizar 
padrões de variação relevantes e avaliar os fatores causais subjacentes (Pires e Vaz, 2010b).

Este artigo se inscreve nos deslocamentos mais recentes do debate sobre participação no Brasil, mas adota uma estratégia metodológica diferente em relação à agenda da efetividade das IPs - mais conservadora, porém cognitivamente mais segura. Trata-se de uma estratégia que foca a produção decisória dos conselhos (outputs), e não seus efeitos sobre as políticas (outcomes), permitindo diagnosticar o que os conselhos estão de fato fazendo e quando o fazem; isto é, que decisões tomam e em que momento de seu ciclo de vida. Padrões decisórios não equivalem a efeitos, mas a análise não precisa se empenhar em demonstrá-los nem postulá-los. A produção decisória diz respeito à capacidade dos conselhos para incidir em políticas públicas; é uma condição necessária, embora, é claro, não suficiente para realizar tal incidência: emitir resoluções não equivale à sua realização, mas, sem decisões orientadas para a definição, a fiscalização ou a gestão da política, não é plausível esperar efetividade. Quando aferida, a produção decisória revela padrões empíricos consistentes, que eventualmente animarão a elaboração de hipóteses informadas por conhecimento mais aprofundado acerca da variação na qualidade do trabalho dos conselhos.

A estratégia analítica descansa em um diagnóstico empírico prévio sobre os tipos de conselho existentes nos municípios do Brasil com base em sua expansão territorial, ao longo de duas décadas, e na maior ou menor presença de mecanismos de indução federal associados a essa expansão (Gurza Lavalle e Barone, 2015). O diagnóstico empírico permite agrupar todos os conselhos presentes na geografia municipal do país em três conjuntos e oferece sustento a uma tipologia conforme critérios dedutivos condizentes com uma análise da produção decisória dos próprios conselhos. Para a realização da análise, e com base em diários oficiais, elaborou-se um "censo" da produção decisória dos conselhos municipais de Guarulhos mediante o mapeamento minucioso de atos administrativos produzidos por eles entre 2005 e 2011. Também se esquadrinhou o levantamento censitário de tais atos estabelecendo padrões decisórios e sua variação entre tipos de conselho e durante seu ciclo de vida. Por fim, aferiram-se os efeitos potenciais dos diferentes tipos de conselho em Guarulhos mediante índices de produção e de incidência em políticas.

O município de Guarulhos, situado na região metropolitana de São Paulo, constitui caso emblemático de gestão participativa entre muni- 
cípios do mesmo porte no Brasil. Governado pelo Partido dos Trabalhadores (PT) desde 2001, o município conta com uma implementação duradoura de OP, sustentada desde sua criação, em 2001, bem como uma estrutura conselhista diversificada, com um total de 33 conselhos em 2011. Quase dois terços desses conselhos foram criados, não de modo fortuito, a partir de 2001. De fato, a experiência participativa de Guarulhos tornou-se reconhecida nacional e internacionalmente nos últimos anos.

Os resultados mostram que a estratégia metodológica adotada é promissora não apenas por sua capacidade de permitir comparações sistemáticas e acúmulo de conhecimento, mas também porque sugere correções importantes nos diagnósticos da literatura sobre o funcionamento dos conselhos. Revelam padrões decisórios consistentes, bem como a importância do ciclo de vida no amadurecimento dos conselhos - entendido como a produção de repertórios de decisões diversificados, balançados e com mais capacidade de incidência em suas respectivas áreas de políticas.

Além desta introdução, o artigo se encontra ordenado em cinco seções. A primeira seção recupera a primeira e a segunda gerações de estudos sobre os conselhos e as preocupações nelas presentes que poderiam se associar à aferição de algum tipo de efetividade das IPs. Também é explorada, com base em resultados de pesquisa recentes, a relação entre indução federal e expansão territorial de tipos específicos de conselho. A segunda seção dialoga com a agenda da efetividade das IPs, justifica as escolhas metodológicas quanto às unidades de observação e agregação, e quanto ao período estudado, bem como o propósito de contornar o problema de causalidade remota enfrentado pela agenda da efetividade das IPs. Igualmente, explicitam-se as limitações da abordagem desenvolvida. Na terceira seção, introduzem-se feições relevantes de Guarulhos para o argumento aqui sustentado. Em seguida, na quarta seção, apresentam-se os resultados dos padrões decisórios encontrados, sua variação ao longo do ciclo de vida dos conselhos, assim como índices que aferem sua produtividade e capacidade de incidência potencial. Por fim, à guisa de conclusão, sintetizam-se os principais achados.

\section{EFETIVIDADE DOS CONSELHOS: UMA QUESTÃO RECENTE?}

O crescimento do número de conselhos é considerado fenômeno inconteste. Na virada dos anos 1990, existiam no Brasil menos de mil conselhos e, duas décadas depois, em 2009, haviam sido implementa- 
dos mais de 27 mil conselhos municipais (IBGE-Munic, 2009). A distribuição territorial é igualmente notável:

Em 1991, apenas na Região Sul havia, em média, mais de um conselho por município. Nove anos depois, todas as regiões brasileiras possuíam mais de 1,5 conselho por município e, em 2010, essa cifra elevou-se para 3,9 no Nordeste, 4 no Norte e mais de 5 no Centro-Oeste $(5,2)$, Sudeste $(5,7)$ e Sul $(5,7)$ (Gurza Lavalle e Barone, 2015).

Essas cifras apenas registram a presença de 17 diferentes conselhos e suas respectivas áreas de políticas no território nacional, mas a variedade de conselhos em operação é maior e abrange mais áreas de políticas do que aquelas cobertas pelo Instituto Brasileiro de Geografia e Estatística (IBGE). Estudos pormenorizados registraram a presença de mais de trinta conselhos nos municípios de São Paulo e Guarulhos (Tatagiba, 2005; Gurza Lavalle, Serafim e Oliveira, 2011), embora, graças às informações do IBGE, seja claro que ambos os municípios têm um número de conselhos muito maior do que a média municipal no Brasil.

O mundo dos significados também evidencia a crescente relevância dessa instância participativa. Nos últimos anos, a palavra "conselhos" acabou por se tornar sinônimo de "conselho gestor de políticas públicas". Em momento tão recente quanto a primeira metade dos anos 2000, os autores que se debruçavam sobre o fenômeno em expansão e ainda incipientemente estudado sentiam necessidade de esclarecer que os conselhos estudados eram um tipo específico de instituição, diferente, por exemplo, dos conselhos populares com tradição em diversas cidades do país e com os quais, supunha-se óbvio, o leitor estaria mais familiarizado (Tatagiba, 2002; Gohn, 2004). Ou seja, há uma década e meia, a sinonímia natural era inversa.

A expansão dos conselhos trouxe consigo diversificação temática ou de áreas de políticas e de modo e grau de inserção nos arcabouços institucionais de tais áreas, plausivelmente alargando a variação de sua eventual efetividade. Se a ampliação do número de conselhos tivesse se atido às áreas consideradas estratégicas pela Constituição, as características derivadas de sua inserção institucional no respectivo setor ou área de políticas guardariam certa semelhança: inscrição em sistemas de políticas, funções de gestão e de controle associadas ao funcionamento regular do sistema, disposição de fundos e elevado grau de institucionalização. Contudo, a expansão dos conselhos como modelo 
preferencial para institucionalizar a participação acarretou não apenas a multiplicação das áreas em que foram implementados - transporte, desenvolvimento urbano, terceira idade, turismo, gênero, raça, cultura, direitos humanos, fármaco-dependência, patrimônio urbano, para mencionarmos apenas alguns casos -, mas também considerável variação quanto à sua inserção institucional no correspondente setor de políticas. Conselhos fracamente integrados no seu setor, por sinal, enfrentam mais dificuldades para granjear efeitos práticos às suas decisões ${ }^{2}$.

De fato, é possível afirmar que existe uma relação estreita entre a integração setorial dos conselhos, sua capilaridade territorial nos municípios do país e a presença de mecanismos fortes de indução federal agindo como motores de sua expansão. Levantamento realizado por Gurza Lavalle e Barone (2015) demonstra que existem três padrões de evolução territorial dos conselhos entre 1989 e 2009: 1) aqueles que tenderam à universalização ao longo de todo o território nacional, impulsionados por mecanismos fortes de indução federal - notadamente repasses condicionados de recursos; 2) conselhos com expansão média, presentes entre $20 \%$ e $60 \%$ dos municípios, cuja expansão - mais acentuada em municípios de índice de desenvolvimento humano (IDH) mais elevado - tem sido estimulada por modalidades moderadas de indução federal; e 3) conselhos com presença territorial baixa (entre 3\% e $17 \%$ dos municípios), amplamente desigual ou exclusiva de municípios de IDH elevado e, no melhor dos casos, apenas associados a formas de indução federal fracas. Assim, o que define esses padrões é o grau de indução federal como mecanismo de expansão, que atua sobretudo por meio da garantia de transferências de recursos através de fundos setoriais cujo uso é condicionado à institucionalização da participação social ${ }^{3}$.

Nos anos 1990, primeira década de expansão dos conselhos, teria parecido demasiadamente otimista imaginar um cenário de expansão assim abrangente. A preocupação central da primeira geração de estudos foi avaliar o funcionamento dos conselhos do ponto de vista de seu potencial democratizante, cuja condição sine qua non era uma efetiva participação. As pesquisas partiram de expectativas exigentes para avaliar uma inovação participativa ainda em processo de invenção, assumindo que devia se tratar de espaços de alargamento do exercício da cidadania, inclusão de setores tradicionalmente excluídos dos circuitos da política formal e ampliação da responsividade das políticas 
às necessidades desses setores. Em formulação sintética, dos conselhos se esperavam genuínas participação e deliberação, aliadas a poder resolutivo. A literatura se debruçou sobre os conselhos se esforçando em mostrar que sua composição e dinâmica internas, bem como a desigualdade de recursos materiais e simbólicos entre conselheiros do governo e da sociedade civil, constituíam empecilhos incontornáveis para uma efetiva participação (Benevides, 1994; Telles, 1994; Cymbalista e Moreira, 2002; Raichelis, 2003) ${ }^{4}$. Dessa perspectiva, a preocupação com a efetividade era em registro democratizante, quer dizer, relacionada aos potenciais de mudança da participação. A questão da incidência em políticas ainda não ocupava o centro das preocupações da literatura, já que a garantia de uma participação efetiva seria um elemento prioritário para assegurar seu potencial democratizante e, parecia plausível supor, nada de relevante seria possível esperar dos conselhos em termos de sua capacidade de incidência se perdurassem as desigualdades acusadas pelos diagnósticos.

A contínua institucionalização dos conselhos e a permanência dos atores neles engajados - a despeito dos diagnósticos críticos imperantes na primeira geração - levaram a literatura a atentar para seus déficits explicativos. Afinal, se os atores continuavam nos conselhos, outras razões que escapavam ao ceticismo da literatura deveriam animá-los. Sugeriu-se o deslocamento para a caracterização das experiências realmente existentes (Tatagiba, 2007a), o que permitiria "lançar pistas acerca do lugar, do papel e da função [do conselho] na política pública" (Tatagiba e Teixeira, 2007a:71; Cortes, 2011; Souto e Paz, 2003). Malgrado a insatisfação, tornou-se preciso entender o que os conselhos efetivamente faziam. Levantaram-se críticas, mas não pela inexistência de participação genuína; antes, pelas implicações das descrições nuançadas do modo de operação dos diferentes conselhos - não raro estudados de um a um. Os diagnósticos da segunda geração de estudos são mistos. Grosso modo, os conselhos de fato efetuariam determinadas tarefas em suas áreas de políticas, consubstanciando certo protagonismo de atores da sociedade civil; entretanto, continuariam desempenhando um papel periférico no momento da definição de políticas (Tatagiba e Teixeira, 2007b; Tatagiba, 2007b; Cortes, 2009; Kayano et al., 2007) ${ }^{5}$. A preocupação com a efetividade na segunda geração de estudos não mais é apenas interna ou focada nos atores da sociedade civil - a existência de participação genuína dos conselheiros -, mas passa a atentar para aspectos do funcionamento setorial dos conselhos e de seu papel nas correspondentes políticas. Em outras pala- 
vras, variáveis institucionais e da comunidade de políticas dos correspondentes setores ganharam relevo para entender as capacidades de incidência dos diferentes conselhos.

Dos diagnósticos oferecidos por ambas as gerações, interessa aqui salientar três aspectos - apontados recorrentemente na literatura - do funcionamento dos conselhos. Desde a primeira geração, salientaram-se (1) o tempo e a energia excessivos dedicados à autorregulação pelos conselhos. A segunda geração tem apontado para (2) a importância das características setoriais da política e, especificamente, para as capacidades maiores de ação dos conselhos inseridos em sistemas de políticas e munidos de fundos próprios. Ademais, a segunda geração também atentou para (3) o papel ambíguo das funções de gestão desempenhadas pelos conselhos.

No que diz respeito à autorregulação (1), a literatura diagnosticou dedicação expressiva do tempo das reuniões e das energias dos conselheiros a discussões relativas às regras e às dinâmicas internas, notadamente à definição de normas para eleições de conselheiros e à elaboração dos regimentos internos (Tatagiba, 2002; Carneiro, 2002). Mais: aferições comparativas com base nas atas de conselhos de grandes capitais e de algumas cidades do interior confirmaram o diagnóstico (Menicucci, 2010; Cunha, 2010). O tom crítico quase sempre associado a tal constatação é facilmente compreensível: a atenção concedida às regras que ordenam as disputas eleitorais e o exercício das atribuições consagradas nas respectivas leis de criação suscitaria suspeição a respeito do tempo e da energia investidos em funções deliberativas e de controle da respectiva política. Com base nesse diagnóstico, poderia ser esperado que os padrões decisórios dos conselhos fossem fortemente desbalanceados ou concentrados na emissão de atos autorregulatórios e que esses atos permanecessem demasiadamente elevados entre todos os tipos de conselho, incluindo os mais antigos - a despeito de cifras algo mais avultadas serem esperáveis nos casos de conselhos de criação mais recente, pelo processo natural de institucionalização.

Quanto às características setoriais (2), não apenas os bens e serviços da respectiva política - passíveis de apropriação seletiva ou pública favoreceriam diferentes formas de ação coletiva por parte dos atores sociais, mas a trajetória do setor comportaria diferentes coalizões de caráter reformista ou não, bem como distintas atribuições conferidas aos conselhos quanto à sua capacidade de incidir na definição, no con- 
trole e na gestão das políticas (Cortes, 2002a; Almeida, 2009). Ademais, seria de índole setorial a percepção dominante dos gestores acerca do papel dos conselhos na política, bem como os tipos de vínculo predominantes entre os profissionais da respectiva área e os atores sociais ou a posição dos conselhos em relação a outras instâncias setoriais abertas à participação, como os fóruns de políticas e as conferências (Cortes, $2002 b$, 2011). Seria de se esperar, conforme tais caracterizações, que os conselhos "históricos" das áreas de saúde, assistência social e direitos da criança e do adolescente registrassem padrões decisórios consistentes com maior capacidade de incidência, enquanto outros conselhos, sem comunidades de políticas com longa história de mobilização social em torno de bens públicos - como a ampliação de direitos - e/ou sem fundos e/ou sem gestores com histórico de engajamento social, acusassem padrões decisórios em maior ou menor medida acanhados.

Por fim, temos a crescente atribuição de funções associadas à gestão administrativa, como a aprovação do registro de entidades e a avaliação de projetos (3). Diversos autores acusaram o caráter burocrático e cartorial adquirido pelo funcionamento dos conselhos, sobretudo nos setores da assistência social e da criança e do adolescente (Teixeira e Tatagiba, 2008; Tatagiba 2007b; Almeida e Tatagiba, 2012; Cortes, 2002a; Paz, 2001). Os receios derivam do fato de tais funções serem a um só tempo expressão de capacidades efetivas de incidência na política e fardo administrativo que consome as energias dos conselheiros, comprometendo a deliberação e o controle social da política de índole propriamente política (Almeida e Tatagiba, 2012). Trata-se de funções ambíguas: se, de um lado, investem os conselhos com atribuições outrora exercidas pela burocracia, outorgando a uma instância de governança participativa protagonismo sem precedentes nas políticas setoriais, de outro trazem consigo uma burocratização dos próprios conselhos, comprometendo suas energias em funções secundárias. Seria de se esperar, conforme tal diagnóstico, que conselhos concentrados na gestão apresentem padrões decisórios pouco diversificados ${ }^{6}$.

\section{A AGENDA DA EFETIVIDADE: UMA ESTRATÉGIA ANALÍTICA CONSERVADORA}

O notável avanço na produção de conhecimento sobre os conselhos foi preponderantemente de índole qualitativa, seguindo a própria evolução expansiva do objeto estudado e decifrando-lhe as feições emergentes. Os esforços de pesquisa dos últimos anos ofereceram uma leitura 
mais nuançada do funcionamento dos conselhos, sensível às suas especificidades sociopolíticas e setoriais. Entretanto, a caracterização dos alcances e das limitações de tais instituições, frequentemente baseada em estudos de caso, assumiu o status de conjecturas ou de implicações plausíveis - porque derivadas de diagnósticos ricos -, mas sem fundamentos sólidos para permitir generalizações. Sabe-se que é da natureza dos estudos de caso, de suas vantagens e desvantagens inerentes, verticalizar o conhecimento à custa de sua generalização ${ }^{7}$.

A agenda da efetividade das instituições participativas (IPs) atenta precisamente para a urgência de se avançar no flanco da generalização do conhecimento acumulado e, de forma mais específica, daquele voltado para o diagnóstico dos efeitos. Visto que a progressiva institucionalização da participação gerou uma nova camada institucional de operação do Estado (Avritzer, 2009; Gurza Lavalle, 2011a; Gurza Lavalle e Isunza Vera, 2011; Pires e Lopez, 2010), conhecer os efeitos dessa nova camada sobre a definição e a operação das políticas se tornou não apenas pertinente, mas imperioso do ponto de vista da gestão pública. Não é fortuito que o Instituto de Pesquisa Econômica Aplicada (Ipea) se tenha empenhado no lançamento dessa agenda (Pires, 2011). As orientações mais gerais são singelas: seria conveniente ir além dos estudos de caso e ampliar o escopo, abarcando mais de uma modalidade de IP e/ ou mais de um setor simultaneamente (Pires e Vaz 2010a, 2010b). De fato, o termo IP, embora cunhado antes (Avritzer, 2008), foi reapropriado pelas iniciativas do Ipea precisamente como uma categoria mais abstrata, capaz de permitir a abordagem simultânea de mais de uma modalidade de inovação participativa.

Todavia, as implicações da agenda da efetividade das IPs para a pesquisa não são triviais. Grosso modo, dois são os desafios: de um lado, inovar no plano metodológico quanto aos observáveis e seu tratamento; de outro, no plano da explicação, estabelecer causalidade. Os trabalhos que até agora contribuíram para avançar empiricamente essa agenda têm se defrontado com os desafios mencionados e procurado contorná-los adotando escolhas inovadoras e estratégias que visam isolar, na medida do possível, o efeito das instituições estudadas sobre variáveis de desempenho de políticas escolhidas (Vaz e Pires, 2011; Pires e Vaz, 2010b).

No que diz respeito ao primeiro desafio, tornou-se pertinente mudar o escopo empírico, a unidade de observação e a unidade de agregação. 
Quanto ao escopo, os estudos centrados em um conselho precisariam ceder passo a abordagens comparativas abrangentes, com ganhos em relação à capacidade de generalização: setores de políticas, IPs ou bem abordagens agregadas de diversos tipos de conselho conforme características não setoriais de interesse - opção aqui seguida. Ademais, o trabalho de comparação e de agregação obrigaria a definir unidades de observação precisas e equivalentes entre conselhos. Assim, processos e práticas, descritos com detalhe pela segunda geração, cederam passo à definição de variáveis independentes, notadamente à construção de índices capazes de ordenar as IPs conforme as qualidades conjecturalmente associadas à sua efetividade - tratada como variável dependente (Avritzer, 2010; Pires e Vaz, 2010b). Por fim, os municípios tornaram-se a unidade de agregação mais comum na agenda da efetividade das IPs, ainda que as estratégias analíticas no tratamento deles variem.

Demonstrar a efetividade das IPs no desempenho de políticas públicas equivale a aferir efeitos esperados e associá-los a uma causa passível de identificação, e que esteja direta ou indiretamente associada ao trabalho dessas instituições. Argumentos de causalidade exigem operações metodológicas das mais complexas e demandantes nas ciências sociais (King, Keohane e Verba, 1994). Seja qual for o aspecto do funcionamento dos conselhos postulado como responsável por sua capacidade de incidência sobre o desempenho de políticas, há inúmeras mediações ou uma distância considerável entre causa e efeito (Gurza Lavalle, 2011b). Por exemplo, entre a deliberação ocorrida em um conselho de saúde ou de educação e o número de leitos hospitalares ou de professores no ensino fundamental de determinado município, há, no melhor dos casos, numerosas mediações possíveis ou distância causal, pois escapa à alçada dos conselhos implementar ou mandar acatar medidas a esse respeito. Embora os avanços na agenda da efetividade tenham apontado para a presença de covariações entre IPs e desempenho positivo de políticas (Pires e Vaz, 2010b), o conjunto de técnicas de controle utilizável para evitar associações espúrias é obstado pela precariedade das variáveis independentes disponíveis no campo dos estudos da participação, bem como pelo conhecimento ainda insuficientemente sistemático sobre aquilo que os conselhos realmente fazem ${ }^{8}$.

Adota-se aqui uma estratégia analítica mais conservadora. Em vez de investir em controles que permitam postular a presença de relações de causalidade entre os afazeres dos conselhos e as variáveis de desempenho de políticas públicas ou de bem-estar (outcomes), privile- 
gia-se como unidade de observação algo que os conselhos realmente fazem: tomar decisões (outputs). O foco nas resoluções de conselhos mediante a análise de atas tem sido uma estratégia de pesquisa adotada para o serviço de propósitos analíticos diversos: avaliação das consequências do desenho institucional, caracterização do exercício da representação, exame das relações de poder entre conselheiros e das dinâmicas internas da deliberação, e até aferição da efetividade deliberativa dos conselhos (Fuks, Perissinotto e Souza, 2004; Avritzer et al., 2005; Cunha, 2007; Pires e Tomás, 2007; Brasil et al., 2013). Vale notar, em consonância com as questões mais recentes da agenda da efetividade das IPs, iniciativas de classificação das temáticas abordadas e decisões tomadas com base em análise de atas (Cunha, 2007, 2009, 2010; Menicucci, 2010; Avritzer et al., 2005). Tais estudos oferecem valiosas pistas sobre o que de fato fazem essas IPs, sem assumir que, com base nas temáticas ou decisões levantadas, é possível derivar efeitos diretos acerca das políticas públicas efetivamente implementadas ou das consequências dessas políticas sobre o bem-estar da população.

Em sintonia com essas iniciativas, avançamos ao desenvolver opções de coleta e análise censitárias, e menos vulneráveis às idiossincrasias do registro de deliberações em atas. Para a observação da atividade decisória dos conselhos de Guarulhos, utilizam-se como unidade de observação os atos administrativos emitidos por eles e publicados no Diário Oficial do município entre janeiro de 2005 e dezembro de $2011^{9}$. Os padrões decisórios a serem examinados descansam em evidências de índole censitária para o período contemplado, quer dizer, foram aferidos todos os conselhos e todos os atos administrativos emitidos por eles. Foram registradas as seguintes classes de atos administrativos: resoluções, comunicados, edital, edital de convocação, edital de retificação, edital de ratificação e parecer.

Resoluções são decisões tomadas por órgão colegiado e, embora raro, podem ser conjuntas quando emitidas por mais de um conselho sobre uma matéria de interesse mútuo. Comunicados frequentemente têm funções homologatórias, não sendo, por conseguinte, meros atos informativos (internos) sobre as atividades dos conselhos ou de outras instâncias ou atores por eles regulados (externos). Meros atos informativos foram desconsiderados. Editais e editais de convocação, ratificação e retificação também dizem respeito a formas de comunicação legal, com funções de homologação nos três primeiros casos e, no último, de correção de atos anteriores. Por fim, o parecer remete ao 
exercício de avaliação das prestações de contas submetidas por órgãos do Executivo municipal ou de atores da sociedade civil vinculados à operação da política, embora não seja o ato administrativo mais utilizado para essa finalidade. A avaliação da prestação de contas de secretarias ou dos fundos setoriais é exercida com mais frequência mediante resolução.

Entre os anos de 2005 e 2011, foram publicados 696 diários oficiais no município de Guarulhos, contabilizando uma média de 99,4 diários por ano ${ }^{10}$. Desses diários, $491(70,54 \%)$ continham ao menos um ato administrativo emitido por algum conselho municipal. Ao todo, foram encontrados 33 conselhos ${ }^{11}$ municipais diferentes, dos quais 23 publicaram pelo menos um ato administrativo no período analisado ${ }^{12}$. Foram produzidos ao todo 1.890 atos envolvendo conselhos municipais: 1.401 emitidos pelos próprios conselhos e 489 pela Prefeitura ou pela Câmara de Vereadores. Dos atos emitidos por conselhos, 1.263 foram classificados dentro das categorias da tipologia de decisões ${ }^{13}$. Nesse universo, foram registradas 679 (53,8\%) resoluções e $18(1,4 \%)$ resoluções conjuntas, $541(43,8 \%)$ comunicados, 14 (1,1\%) editais e editais de convocação, e $10(0,8 \%)$ pareceres ${ }^{14}$.

A delimitação do período estudado equivale a uma gestão municipal completa (2005-2008) e a três anos da gestão seguinte, em curso no momento da coleta de dados (2009-2011). Restringiu-se o período dessa forma por motivos analíticos e operativos. No plano analítico, procurou-se contexto favorável à proliferação e à operação de conselhos contemplando mais de uma administração para permitir possíveis variações nos padrões decisórios eventualmente associadas às eleições municipais. Contudo, não foram encontradas variações na atividade decisória dos conselhos durante a eleição coberta e não há indícios de que a ampliação do período contemplado teria alterado os padrões encontrados ${ }^{15}$. Ademais, conforme será visto adiante, a dimensão temporal que aqui recebe tratamento - o ciclo de vida dos conselhos - é endógena e, portanto, não remete a aspectos conjunturais do contexto, mas sim a uma temporalidade própria da operação dessas IPs. No plano operativo, trata-se de caso piloto para o desenvolvimento não apenas de uma metodologia de coleta, mas, sobretudo, de tipologias de resoluções passíveis de serem aplicadas a censos sobre a produção decisória de outros municípios ${ }^{16}$. O tempo longo demandado pelo desenvolvimento e pela classificação tipológica dos atos administrativos 
e as vantagens de se iniciar a fase comparativa levaram a encerrar a coleta no sétimo ano.

Duas condições definem a inclusão de conselhos na análise: emissão de pelo menos um ato administrativo no período estudado ou ter sido matéria de ato administrativo do Executivo ou do Legislativo municipal nesse tempo. Isso significa que conselhos eventualmente criados antes de 2005, inativos e que não foram matéria sequer de um ato do poder público entre 2005 e 2011 não constam do cômputo. A inatividade não equivale à extinção e, por isso, nada permite inferir a respeito da sobrevivência ou da mortalidade dos conselhos - assunto ainda pouco explorado na literatura ${ }^{17}$.

Os conselhos foram agrupados de acordo com o diagnóstico de sua evolução territorial nos municípios do país (Gurza Lavalle e Barone, 2015). Os padrões da expansão territorial receberam atenção na seção anterior, agora cabe apenas sintetizar a tipologia dedutiva que ordenará a análise. Note-se que a consistência dos padrões de expansão territorial dos conselhos, considerando a totalidade dos municípios no país, revelou a importância da indução federal como mecanismo de difusão. A tipologia eleva ao plano analítico de uma tipologia dedutiva útil para a construção e teórica - o papel da indução federal e as características correlatas encontradas nos respectivos conjuntos de conselhos. O primeiro tipo (C1) é constituído por conselhos tendentes à universalização e à estabilização graças à alta indução federal e cuja inserção em sua respectiva área de política é mais bem-estruturada. Dos 33 conselhos registrados em Guarulhos, sete foram classificados nesse grupo. O segundo tipo (C2) contempla conselhos com expansão territorial média e indução federal moderada, não raro inscritos em políticas com um grau menor de estruturação se comparadas às políticas que funcionam como sistemas e cuja inserção na operação regular de seu respectivo setor é também moderada. Registraram-se cinco conselhos nessa categoria. Por fim, o terceiro tipo (C3) compreende conselhos pouco difundidos, objeto de indução federal fraca, na melhor das hipóteses, e amiúde criados ao sabor de eventos e de questões de interesse municipal e conforme as prioridades políticas da situação ou da oposição locais. Assim, os conselhos desse tipo têm funções facultativas e níveis de integração à operação da administração tendencialmente modestos. A maioria dos conselhos de Guarulhos, nada menos que 21, corresponde a essa categoria. A classificação completa dos conselhos pode ser verificada no Quadro 1. 
Sem dúvida, as atribuições dos conselhos e sua potencial incidência sobre políticas públicas variam conforme o setor de políticas, tal e como mostrado pela literatura da segunda geração (Cortes, 2002a, 2009). Optar por uma análise agregada dos conselhos com base na tipologia descrita anteriormente limita a capacidade de contemplar de forma sistemática, nesta análise, a dimensão setorial e os padrões decisórios de conselhos específicos. A tipologia descansa em base empírica sólida e permite uma compreensão dos conselhos em um plano analítico mais agregado. No entanto, existe covariação entre, de um lado, indução federal e algumas das características correlatas da tipologia de conselhos e, de outro, setores específicos de políticas. Assim, e de modo que favoreça a parcimônia na análise, apenas alusões pontuais à dimensão setorial serão realizadas oportunamente quando permitirem enriquecer a compreensão dos resultados agregados pela tipologia de conselhos.

Conforme será mostrado nas páginas seguintes, há ganhos cognitivos valiosos na estratégia exposta nesta seção, mas ela também impõe limitações. Sem dúvida, padrões decisórios não podem ser simplesmente interpretados como efetividade; nem aqui se sugere tal leitura. Igualmente, escapam da unidade analítica privilegiada neste artigo a qualidade do trabalho e da deliberação nos conselhos, bem como o conflito interno que pode alterar o conteúdo das decisões publicadas no Diário Oficial ou até levar a não produzi-las. Há diferenças entre aquilo que vem à luz no Diário Oficial e práticas eventualmente relevantes dos conselhos - debates e mesmo decisões - que não requerem publicação. Todos esses são "pontos cegos" da estratégia analítica adotada. Nesse sentido, não são contempladas na análise, por exemplo, as dinâmicas deliberativas internas aos conselhos nem o trabalho das comissões de conselheiros responsáveis pela elaboração de propostas para deliberação do pleno, preparação de relatórios e monitoramento e fiscalização das ações e dos programas implementados pelo poder público local. A análise dessas dimensões requereria a adoção de desenho de pesquisa e unidade de análise distintos.

\section{GUARULHOS: UM CENÁRIO FAVORÁVEL ÀS INSTITUIÇÕES PARTICIPATIVAS}

Com 1.221.979 habitantes, Guarulhos é um município economicamente pujante. Seu produto interno bruto (PIB) o situa como nona economia do Brasil (IBGE, 2012). Também é um cenário favorável à partici- 
pação social em virtude de sua história política no período pós-transição e, em especial, depois da chegada do Partido dos Trabalhadores (PT) ao Poder Executivo. Durante a ditadura, a Prefeitura estimulou a organização da demanda ou dos reclamos dispersos dos habitantes das periferias com a criação de associações de bairro para processar e coordenar os pleitos e as petições dos assentamentos irregulares em expansão acelerada (Leandro Silva, 1998:75-107, 41-51; Pietá, 1992:67-77). Isso imprimiu uma dinâmica mobilizatória à disputa pelos eleitores desses vastos assentamentos mediante o uso de associações de bairro e de suas lideranças como cabos eleitorais, e estimulou os principais partidos políticos no período da pós-transição, quando no governo, a avançar na institucionalização da participação (Gurza Lavalle et al., 2011).

Guarulhos teve tradicionalmente governos de centro-direita. Depois da transição, foi governado pelo Partido do Movimento Democrático Brasileiro (PMDB) (três gestões) e, em seguida, registrou uma gestão fugaz do Partido Democrático Trabalhista (PDT) (1997), interrompida por escândalos de corrupção e completada pelo Partido Verde (PV) (1998-2000). Durante as gestões do PMDB, a mobilização popular por meio das associações de bairro foi amplamente estimulada pela gestão municipal, que também criou uma entidade com funções de intermediação e de regularização jurídica para essas associações (Ranali, 2002:227-239), bem como implementou conselhos e até o orçamento participativo (OP). Conforme mostrado no Quadro 1, as três gestões do PMDB criaram nove conselhos, a maioria deles de interesse municipal e sem incentivos federais fortes capazes de induzir sua criação e estabilização (nesse sentido, classificados no tipo 3).

Após longo investimento político, também envolvendo mobilização popular, o PT derrotou o PMDB. Desde 2001, Guarulhos é governado por esse partido que, entre 2011 e 2015, exerceu seu quarto mandato consecutivo e, ao longo dos anos, investiu em programas de governo comprometidos com a participação social e o combate à corrupção tema caro ao município em virtude dos escândalos ocorridos nas gestões anteriores. O PT incrementou notavelmente o número de conselhos em suas gestões, criando 21 dos 33 conselhos registrados no município (ver Quadro 1). Também foi criado o Núcleo de Participação Popular na estrutura administrativa da Prefeitura com o intuito de coordenar e promover a participação cidadã, e refundado o OP. Mais: o município se tornou referência por contar com uma experiência de OP 
inovadora graças à introdução de tecnologia e de um ciclo bienal, por ter coordenado durante dois anos (2011-2012) a Rede Nacional do OP, pela diversificação de sua estrutura conselhista e por sua participação como membro da rede UrBal - que internacionalizou o OP no início dos anos 2000 -, situando Guarulhos entre os municípios brasileiros cujas experiências de inovação foram internacionalmente reconhecidas como boas práticas de governança participativa no nível local (Gurza Lavalle et al., 2011).

O Quadro 1 sistematiza os conselhos criados por mandato, as siglas que os identificam (utilizadas na seção seguinte), os respectivos prefeitos e partidos, bem como a classificação de cada conselho na tipologia aqui empregada e o número de atos emitidos e passíveis de classificação no período estudado.

\section{PADRÕES DECISÓRIOS E CICLO DE VIDA DOS CONSELHOS EM GUARULHOS}

\section{Conselhos, Tipos e Atividade Decisória}

O primeiro conjunto de resultados é acerca da distribuição das decisões coletadas e acusa uma atuação francamente desigual dos conselhos, por vezes inesperada. Observam-se alguns conselhos comparativamente hiperativos, como o CMAS e o CMDCA, com mais de 450 decisões emitidas cada um, enquanto outros conselhos nem sequer produziram seis atos administrativos ao longo dos sete anos estudados. Nada menos que 18 dos 33 conselhos estudados se encontram nessa posição, com uma média inferior a uma decisão emitida por ano. Isso em um contexto altamente favorável ao funcionamento de instituições participativas (IPs). Mais: foram encontrados nove conselhos que consideramos inativos, pois, embora criados no período estudado, não emitiram nenhuma decisão. Entre eles, apenas dois (Comdema e CMD) foram criados antes de 2006, ou seja, a maioria foi criada depois da ascensão do PT à Prefeitura.

O comportamento médio da produção decisória é consoante com a tipologia, acusando volume desigual da produção de decisões entre tipos de conselho, embora registre dispersão interna em cada tipo nem sempre afinada aos padrões esperados segundo a tipologia de conselhos. No período estudado, quase todos os conselhos inativos com exceção de apenas um caso (Comdema) - pertencem ao tipo C3; isto é, foram criados por iniciativa municipal, na melhor das hipóteses 
Adrian Gurza Lavalle, Jessica Voigt e Lizandra Serafim

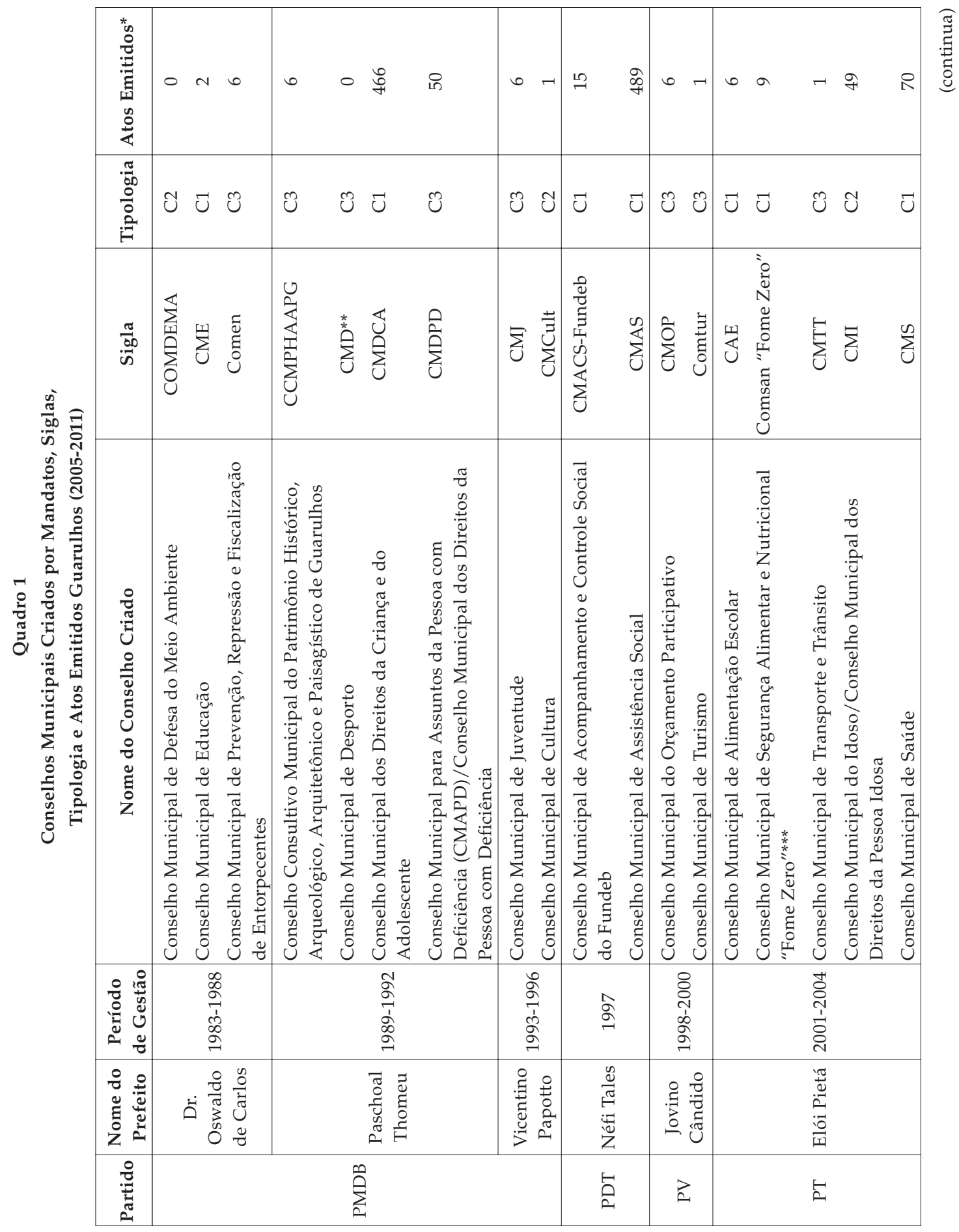

626 DADOS - Revista de Ciências Sociais, Rio de Janeiro, vol. 59, no 3, 2016 
Afinal, o que Fazem os Conselhos e Quando o Fazem?

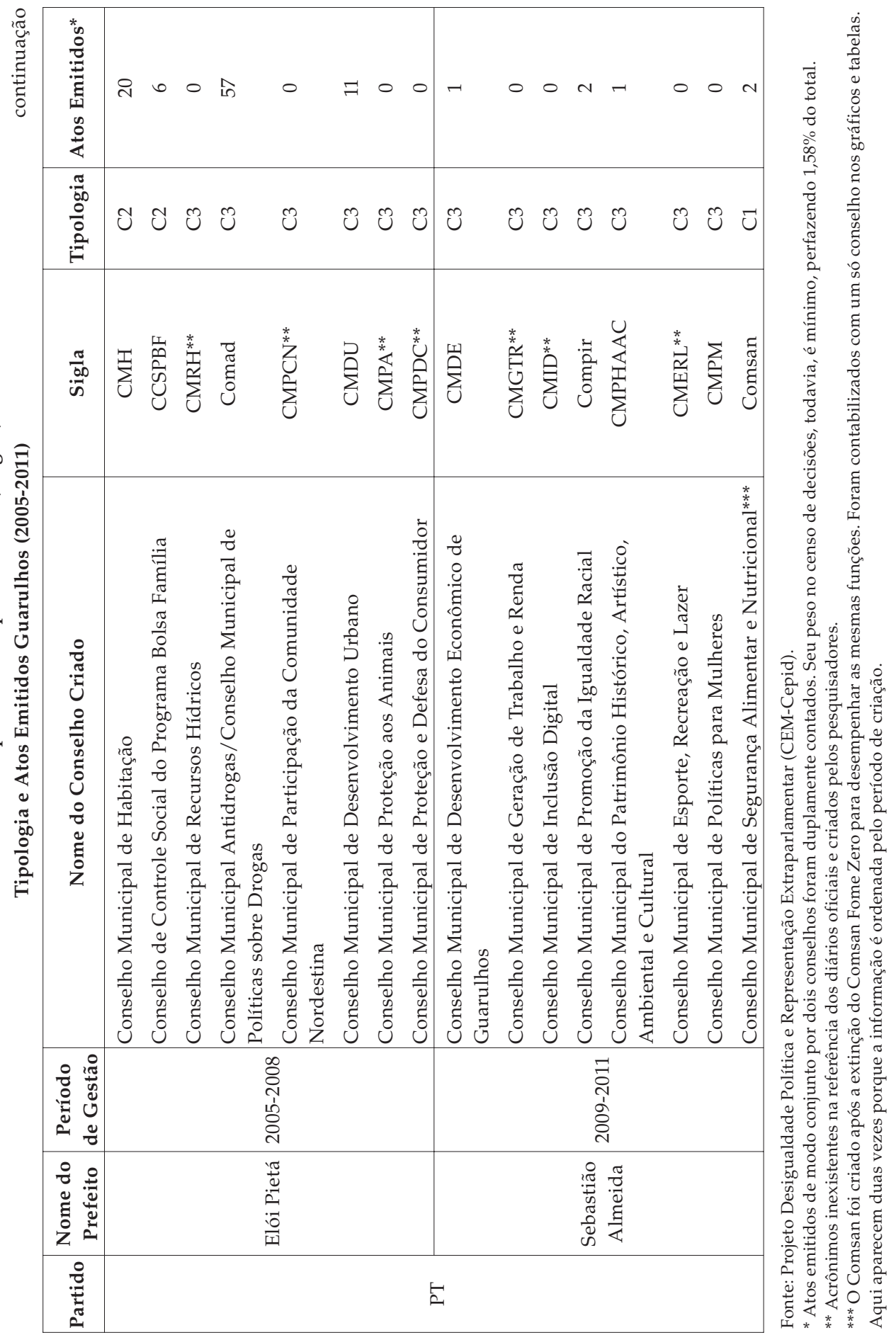

DADOS - Revista de Ciências Sociais, Rio de Janeiro, vol. 59, nº 3, 2016 
sob indução federal fraca, e operam com um grau modesto de integração à correspondente política. Com mais precisão, $40 \%$ dos conselhos do tipo C3 são inativos. Por sua vez, os conselhos do tipo $\mathrm{C} 1(\mathrm{~N}=7)$ tomaram e publicaram $82,54 \%$ das decisões. O CMS apresenta cifras algo avultadas (70 atos), mas nada que se compare à hiperatividade dos dois "carros-chefe" dos conselhos agrupados no tipo C1, o CMAS (489 atos) e o CMDCA (466 atos), os quais praticamente sozinhos perfilam o padrão decisório dos conselhos desse grupo. Os conselhos do tipo C2 $(\mathrm{N}=5)$ tomaram $5,92 \%$ das decisões; e os do tipo $\mathrm{C} 3(\mathrm{~N}=21), 11,54 \%$.

Há casos que escapam do comportamento esperado, mas, convém reiterar, a tipologia é de índole dedutiva. Enquanto o CMDPD e o Comad, do tipo $\mathrm{C} 3$, emitiriam por volta de 50 atos cada, o CMH, do tipo $\mathrm{C} 2$, produziu menos da metade disso - apenas 20 atos -, e o Comdema, também do tipo $C 2$, não produziu sequer uma decisão, embora o CMI tenha produzido quase 50. Igualmente notórias são as cifras mínimas de conselhos de tipo C1, como o CME (2 atos), o CAE (6 atos) e o CMACS-Fundeb (15 atos), ligados à área de educação. O Quadro 2 sintetiza a dispersão dos atos emitidos em cada categoria da tipologia de conselhos. É possível que a análise comparativa de outros municípios verifique a existência de padrões de atividade decisória estáveis entre os três tipos de conselho, e há indícios nessa direção (Gurza Lavalle et al., 2015), o que reconduziria o exame das variações inesperadas de um município - dentro do padrão geral - a fatores da administração pública local. No caso de Guarulhos, por exemplo, conselhos com considerável produção (CMAS, CMDCA, CMI, CMDPD, Comad) tem suas atividades - reuniões e burocracia - coordenadas no espaço denominado "Casa dos Conselhos"18, o que pode favorecer seu funcionamento. É claro que a disparidade de atividade decisória entre conselhos do mesmo tipo, especialmente no grupo associado à alta indução federal, também guarda relação com as funções distintivas a eles atribuídas nos respectivos setores de políticas. Tanto o CMAS quanto o CMDCA foram investidos com atribuições que demandam a emissão contínua de atos administrativos - registro, homologação e alteração do cadastro de entidades facultadas para receber recursos públicos; gestão de projetos e/ou aprovação ou recusa de convênios que envolvem atores da sociedade civil etc. ${ }^{19}$

\section{Padrões Decisórios e Tipos de Conselho}

O segundo conjunto de resultados diz respeito aos tipos de decisões tomadas pelos conselhos. Os atos administrativos foram classificados 


\section{Quadro 2}

Conselhos, Atos Emitidos, Média e Desvio-padrão por Tipo de Conselho

Guarulhos (2005-2011)

\begin{tabular}{|c|c|c|c|}
\hline $\begin{array}{l}\text { Incidência Federal/Sigla } \\
\text { do Conselho* }\end{array}$ & Atos Emitidos** & $\begin{array}{c}\text { Média de Atos } \\
\text { Emitidos por Categoria }\end{array}$ & Desvio-padrão \\
\hline \multicolumn{4}{|c|}{ C1 - Alta indução federal } \\
\hline $\begin{array}{l}\text { CAE } \\
\text { CMACS-Fundeb } \\
\text { CMAS } \\
\text { CMDCA } \\
\text { CME } \\
\text { CMS } \\
\text { Comsan } \\
\end{array}$ & $\begin{array}{c}6 \\
15 \\
489 \\
466 \\
2 \\
70 \\
11\end{array}$ & 151 & 207,485 \\
\hline \multicolumn{4}{|c|}{ C2 - Indução federal moderada } \\
\hline $\begin{array}{l}\text { CCSPBF } \\
\text { CMCult } \\
\text { CMH } \\
\text { CMI } \\
\text { Comdema } \\
\end{array}$ & $\begin{array}{c}6 \\
1 \\
20 \\
49 \\
0\end{array}$ & 15 & 18,3456 \\
\hline \multicolumn{4}{|c|}{ C3 - Indução federal fraca } \\
\hline $\begin{array}{l}\text { Comen } \\
\text { CCMPHAAPG } \\
\text { CMDE } \\
\text { CMDPD } \\
\text { CMDU } \\
\text { CMJ } \\
\text { CMOP } \\
\text { CMPHAAC } \\
\text { CMTT } \\
\text { Comad } \\
\text { Compir } \\
\text { Comtur } \\
\text { CMD } \\
\text { CMRH } \\
\text { CMPCN } \\
\text { CMPA } \\
\text { CMPDC } \\
\text { CMGTR } \\
\text { CMID } \\
\text { CMPM } \\
\text { CMERL }\end{array}$ & $\begin{array}{c}6 \\
6 \\
1 \\
50 \\
11 \\
6 \\
6 \\
1 \\
1 \\
57 \\
2 \\
1 \\
0 \\
0 \\
0 \\
0 \\
0 \\
0 \\
0 \\
0 \\
0\end{array}$ & 7 & 15,3978 \\
\hline
\end{tabular}

Fonte: Projeto Desigualdade Política e Representação Extraparlamentar (CEM-Cepid).

* Não contém atos emitidos conjuntamente por mais de um conselho.

** Não contém atos que retificam atos anteriormente publicados e atos repetidos. 
em uma tipologia com cinco categorias, especificadas com o intuito de iluminar o repertório decisório do ponto de vista do momento da incidência e das matérias sobre as quais se objetiva incidir.

O tipo 1, "definição geral da política" (14,09\% dos atos em Guarulhos), envolve: definição de diretrizes e / ou normas para orientá-la, estabelecimento de objetivos, metas e/ou resultados esperados da gestão, aprovação de programas e políticas e solicitação de mudanças a instâncias supramunicipais - responsáveis pelo financiamento de programas - nas metas e/ou critérios de atendimento. Trata-se de atos que visam incidir na política ex ante pela estipulação dos termos gerais de sua operação.

O tipo 2, "fiscalização da política" (8,79\%), contempla ações de vigilância, sanção e veto a órgãos da administração e a agentes executores da política mediante medidas que objetivam incrementar a transparência ou exprimem avaliação acerca da prestação de contas de tais órgãos ou agentes. Nesse caso, os atos se propõem a incidir na política ex post ${ }^{20}$.

O tipo 3, "gestão administrativa" (34,92\%), remete a atividades de operação regular ou a trâmites da política, como certificação e registro de entidades da sociedade civil, homologação de procedimentos e decisões ou simplesmente a publicação de informações de curso legal. Nesse caso, a discricionariedade do conselho é menor e trabalha na avaliação de casos e na aplicação dos critérios que regulam os trâmites pertinentes. A incidência na política ocorre de forma indireta, isto é, pelos efeitos que pode suscitar na política o exercício das atribuições de tramitação ${ }^{21}$.

O tipo 4, "autorregulação e autogestão" (36,5\%), engloba decisões a respeito do funcionamento interno do conselho e da conduta de seus conselheiros, como determinação do calendário de funcionamento, criação de instâncias internas de divisão do trabalho, regulamentação e supervisão das eleições ou definição do regimento interno. Trata-se de decisões cuja matéria são a própria organização e o funcionamento interno do conselho. Por isso, remetem mais às disputas sobre o papel do conselho e do perfil dos atores facultados a pleitear cadeiras do que à incidência sobre a respectiva política setorial.

O tipo 5, "regulação de outras instâncias" que envolvem participação (5\%), compreende decisões de regulação e de supervisão sobre instâncias setoriais que envolvem participação da sociedade civil, notada- 
mente conferências municipais - mas não só, também instâncias submunicipais de participação, como comitês de programas ou instâncias colegiadas ad hoc. Com mais precisão, o tipo remete à definição de critérios para a organização e o funcionamento de tais instâncias, à definição de representantes, à fiscalização de suas ações e à regulação de seus processos eleitorais. Também nesse caso a eventual incidência sobre a política é indireta.

As categorias "gestão administrativa" e "autorregulação e autogestão" ocupam lugar preponderante nos atos emitidos pelos conselhos de Guarulhos: 19 cada, se calculado o número médio de decisões por conselho ativo (Tabela 1). O peso de ambos os conjuntos de atos administrativos já foi apontado e questionado pela literatura, embora seja aceito que as funções de gestão administrativa constituem uma categoria ambígua, pois suas operações de gerenciamento consomem energia e tempo, mas simultaneamente implicam o controle sobre aspectos não trivias da política. Ainda que de modo menos expressivo, o padrão decisório dos conselhos também compreende outras funções que poderiam ser qualificadas sem dúvida como substantivas, pois visam incidir na política ex ante ou ex post - ou em outras instâncias participativas com tal capacidade de incidência. Nos conselhos de tipo C1, esses atos administrativos considerados em conjunto perfazem um número médio superior ao daqueles orientados para a autorregulação. Aproximadamente um terço do número total de decisões pertence a essas outras categorias que têm merecido menos atenção na literatura.

Tabela 1

Número Médio de Decisões por Conselho Ativo (Conselhos do Tipo C1, C2 ou C3) e Tipologia de Decisões Guarulhos (2005-2011)

\begin{tabular}{l|c|c|c|c}
\hline \multirow{2}{*}{ Tipo de Decisão } & \multicolumn{4}{|c}{ Atos/Conselhos Ativos } \\
\cline { 2 - 5 } & $\begin{array}{c}\text { Conselho } \\
\text { do Tipo C1 }\end{array}$ & $\begin{array}{c}\text { Conselho } \\
\text { do Tipo C2 }\end{array}$ & $\begin{array}{c}\text { Conselho } \\
\text { do Tipo C3 }\end{array}$ & Total \\
\hline 1. Definição geral da política & 21,29 & 3,25 & 0,42 & 7,26 \\
2. Fiscalização da política & 15,43 & 0,25 & 0,08 & 4,78 \\
3. Gestão administrativa & 60,00 & 1,25 & 1,17 & 19,09 \\
4. Autorregulação e autogestão & 41,00 & 12,50 & 9,92 & 19,83 \\
5. Regulação de outras instâncias & 7,00 & 1,25 & 0,58 & 2,65 \\
\hline Total* $^{\quad N}$ & $\mathbf{1 4 4 , 7 1}$ & $\mathbf{1 8 , 5 0}$ & $\mathbf{1 2 , 1 7}$ & $\mathbf{5 3 , 6 1}$ \\
& $\mathbf{1 . 0 1 3}$ & $\mathbf{7 4}$ & $\mathbf{1 4 6}$ & $\mathbf{1 . 2 3 3}$ \\
\hline
\end{tabular}

Fonte: Projeto Desigualdade Política e Representação Extraparlamentar (CEM-Cepid).

*Não contempla decisões emitidas simultaneamente por mais de um conselho nem decisões classificadas na categoria residual "outras". 
A Tabela 1 também mostra o padrão decisório por tipo de conselho, organizando os atos emitidos de cada categoria pelos conselhos ativos nos correspondentes tipos ${ }^{22}$. Como já mencionado, os conselhos do tipo $\mathrm{C} 1$ são notoriamente mais ativos: produziram, em Guarulhos e em média, cerca de quatro vezes mais decisões do que os demais conselhos juntos. Vale notar que os conselhos do tipo C1 são os únicos em que as funções de gestão adquirem relevo, a ponto de apresentarem cifras maiores que os atos de autorregulação e autocontrole. De fato, e enquanto os atos de "autorregulação" representam dois terços daqueles orientados à "gestão" nos conselhos $\mathrm{C} 1$, a relação se inverte acentuadamente no caso dos outros dois tipos de conselho, que produzem 10 (C2) e 8 (C3) vezes mais atos de autorregulação. Ademais, as decisões de "definição da política" e "regulação de IPs" são menos relevantes no caso desses dois tipos de conselho; e as de "fiscalização da política", francamente insignificantes. A esse respeito, o padrão decisório do CMAS e do CMDCA é determinante.

\section{Ciclo de Vida dos Conselhos e Padrões Decisórios}

O terceiro e último conjunto de resultados compreende a variação dos padrões decisórios em relação ao ciclo de vida dos conselhos, bem como o comportamento de índices de produtividade e incidência quando considerada sua "idade". O tempo no ciclo de vida é endógeno ao funcionamento dos conselhos, quer dizer, não remete ao contexto por exemplo, eleições municipais - e a seus efeitos sobre a atividade decisória, mas às decisões tomadas por diferentes conselhos quando tinham os mesmos anos de vida, mesmo que em momentos "históricos" distintos. Em outras palavras, não se trata do contexto ou do tempo do "mundo" afetando exogenamente o funcionamento dos conselhos, mas de uma temporalidade própria ao amadurecimento dos conse$\operatorname{lhos}^{23}$. Os três gráficos a seguir apresentam a média de atos administrativos emitidos ano a ano ao longo do ciclo de vida dos conselhos ${ }^{24}$. Note-se que as cifras são médias relativas à quantidade de conselhos ativos no período estudado. Cabe mencionar, e sempre em relação a 2011, que os conselhos do tipo C1 registraram uma idade média de 12,8 anos; os do tipo C2, de 12,2 anos; e, por fim, aqueles do tipo C3, de 8,3 anos.

Dada a concentração de decisões em conselhos do tipo C1, eles acabam por delinear o padrão médio da produção total dos conselhos, mas existem diferenças específicas relevantes entre os diferentes tipos. No 
Gráfico 1, dedicado aos conselhos do tipo C1, vê-se que a té o oitavo ano de idade há um contingente baixo de decisões tomadas. A partir desse ano, há um aumento significativo de todos os tipos de ato emitidos pelos conselhos, alcançando um pico de mais de 50 decisões de gestão quatro anos depois. Com esse lapso, a média de atos de autorregulação por ano apresenta número de decisões superior a 7 para o restante da série. Chama mais a atenção a evolução das decisões de gestão administrativa que, após despontar, se tornam o tipo de ato predominante para a maioria dos anos seguintes. Dois tipos de ato com capacidade de incidência direta nas políticas - definição e fiscalização da política apresentam trajetórias de crescimento e declínio semelhante, com ápice entre os 11 e 13 anos de vida, e depois queda progressiva. Por fim, as decisões de regulação de outras IPs emergem no mesmo momento do ciclo de vida que a maior parte dos outros tipos de ato, mas seu crescimento é mais vagaroso e oscilante.

Com o propósito de permitir a visualização da evolução do padrão decisório ao longo do ciclo de vida dos conselhos do tipo C2, alterou-se a

\section{Gráfico 1}

Padrões Decisórios: Distribuição dos Tipos de Decisão pelo

Ciclo de Vida dos Conselhos (C1)

Guarulhos (2005-2011)

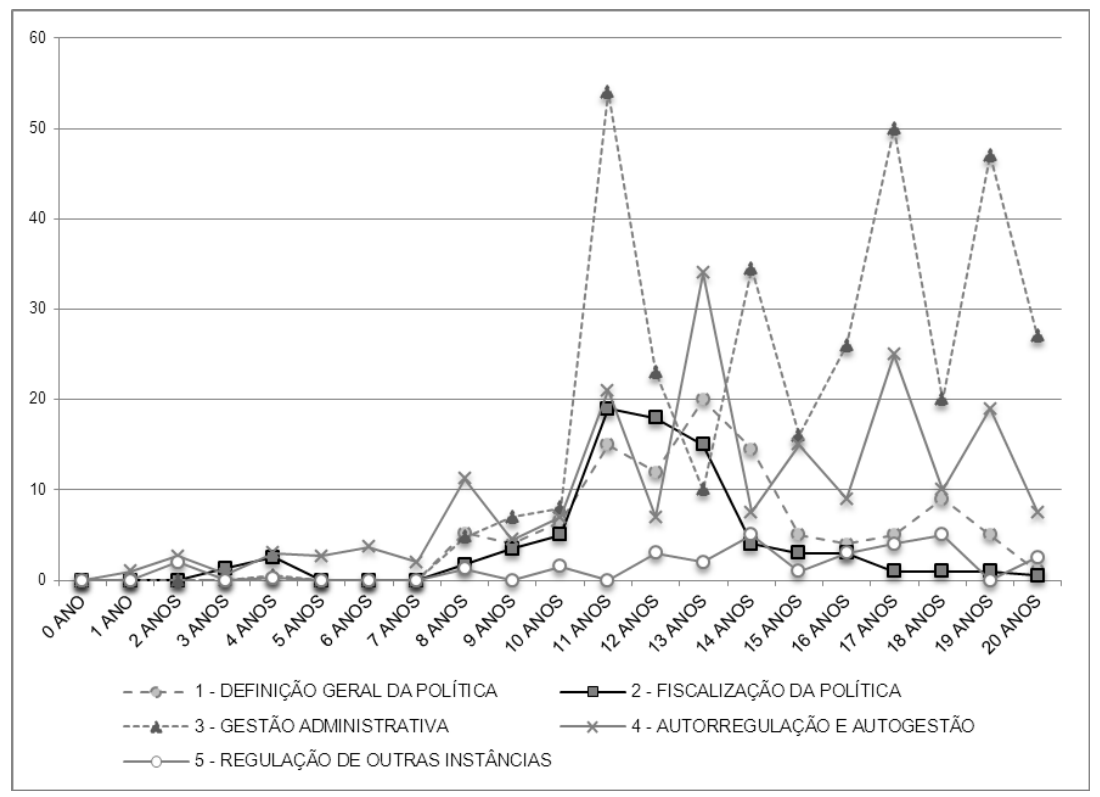

Fonte: Projeto Desigualdade Política e Representação Extraparlamentar (CEM-Cepid).

DADOS - Revista de Ciências Sociais, Rio de Janeiro, vol. 59, n 3, 2016 


\section{Gráfico 2}

Padrões Decisórios: Distribuição dos Tipos de Decisão pelo Ciclo de Vida dos Conselhos (C2)

Guarulhos (2005-2011)

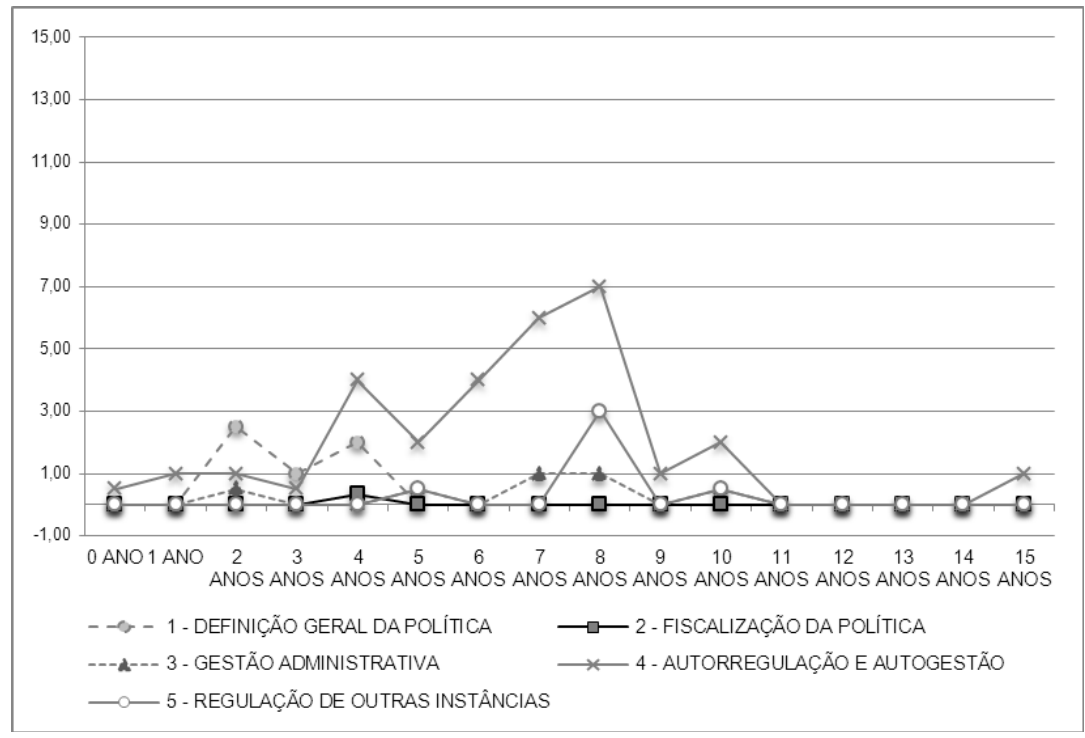

Fonte: Projeto Desigualdade Política e Representação Extraparlamentar (CEM-Cepid).

escala, de modo que as variações são amplificadas, aparentando quatro vezes o tamanho que teriam se plotadas na escala do primeiro gráfico. Foram considerados quinze anos, pois nesse grupo existem apenas dois conselhos mais longevos; além disso, representar um período maior induziria a uma leitura errada de declínio abrupto das atividades decisórias do conjunto. A análise permite perceber imediatamente que o volume proporcional da produção decisória dos conselhos do tipo C2 é bem menor. Enquanto a média anual de atos emitidos pelos conselhos ativos do tipo $\mathrm{C} 1$ apresenta um pico de mais de cem decisões em um mesmo momento - se somados todos os atos administrativos emitidos no décimo primeiro ano de vida--, a média dos conselhos com indução federal mediana registra um pico de apenas sete decisões em seu melhor ano. O padrão decisório inicial é diferente: a emergência de atividade decisória nos conselhos é anterior, embora menos diversificada, e não se verifica explosão de decisões no oitavo ano de vida. Isso decorre da distribuição das idades dos conselhos desse tipo, pois, a despeito de registrarem média de doze anos de vida, apenas dois deles (CMCult e CMI) passam os sete anos. 


\section{Gráfico 3}

Padrões Decisórios: Distribuição dos Tipos de Decisão pelo Ciclo de Vida dos Conselhos (C3)

Guarulhos (2005-2011)

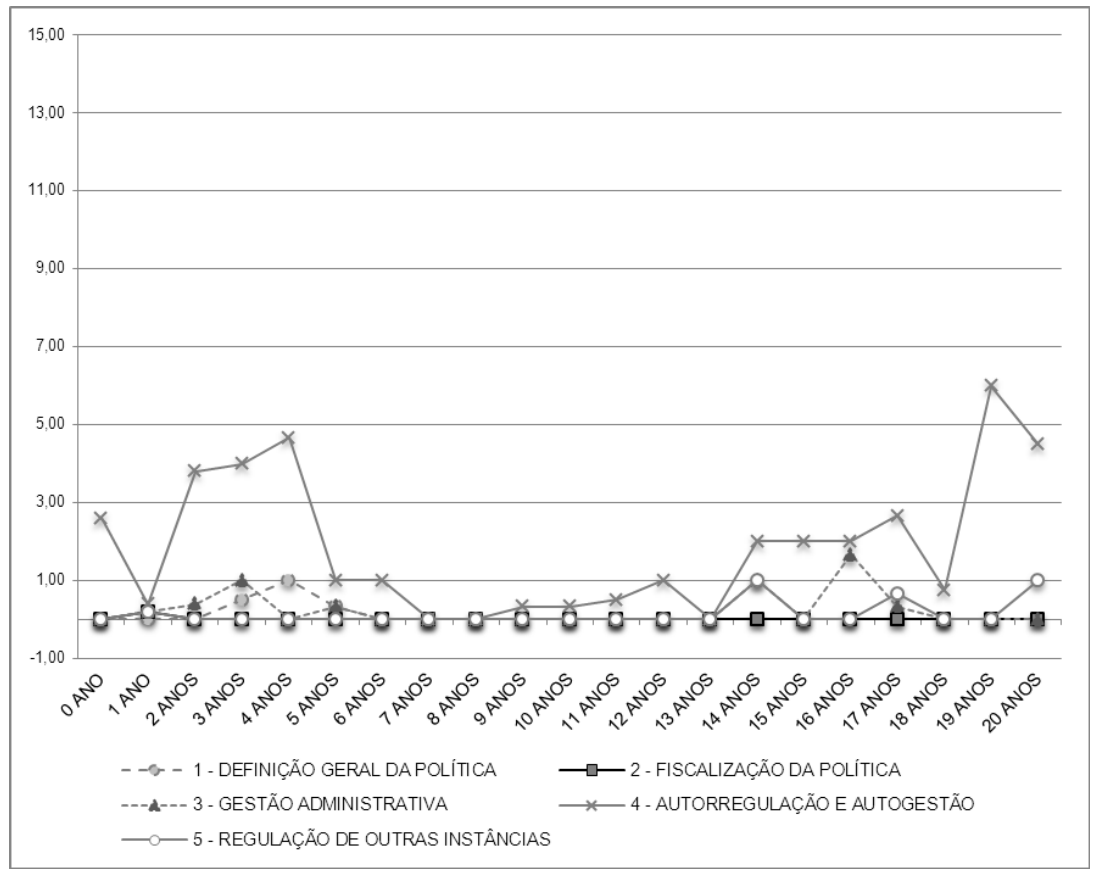

Fonte: Projeto Desigualdade Política e Representação Extraparlamentar (CEM-Cepid).

Novamente, a escala permanece magnificada quatro vezes em relação ao primeiro gráfico, mas idêntica ao segundo. Observando os conselhos do tipo C3, percebe-se um volume médio de decisões por ano ainda menor e uma presença maior, embora insignificante, das decisões de autorregulação. Diferentemente dos outros dois tipos, conselhos com fraca indução federal e de interesse municipal parecem demandar um processo de maturação maior, pois, em seu modesto perfil de atividade, a diversificação decisória registra-se apenas a partir de catorze anos.

A distribuição do padrão decisório ao longo do ciclo de vida pode adquirir contornos mais claros se expressa de modo sintético e comparando as proporções entre conjuntos maiores de decisões. Foram desenvolvidos dois índices à procura de métricas de produtividade e incidência potencial em políticas para avaliar os padrões decisórios dos conselhos ${ }^{25}$. Primeiramente, e em diálogo com os receios suscita- 


\section{Gráfico 4}

Distribuição do Índice de Produtividade dos Tipos de Conselho (C1, C2 e C3) pelo Ciclo de Vida Guarulhos (2005-2011)

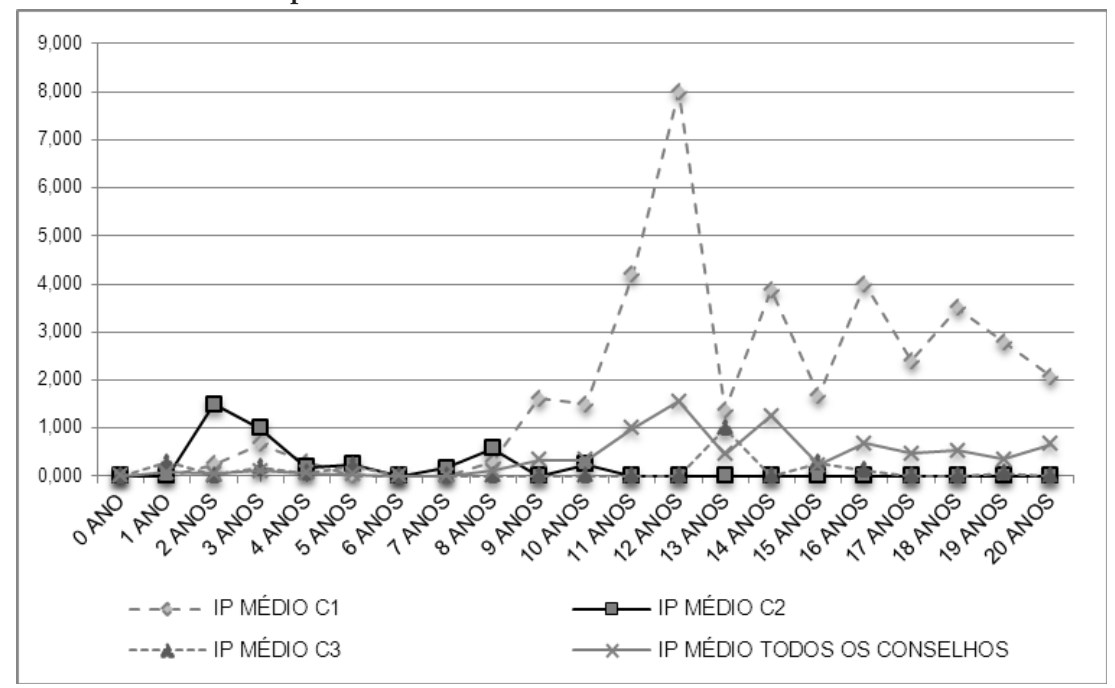

Fonte: Projeto Desigualdade Política e Representação Extraparlamentar (CEM-Cepid).

dos na literatura pelo peso dos atos de autorregulação, comparamos o peso de tais atos em relação às demais decisões. Para tanto, formulou-se um Índice de Produtividade dos Conselhos (IProd) ${ }^{26}$, assumindo que, quanto maior a proporção de atos de autorregulação e de autogestão, menor a produtividade dos conselhos. Note-se que o valor 1 define o limiar a partir do qual o conjunto de atos administrativos emitidos supera as decisões de autorregulação.

Como nos gráficos anteriores, percebe-se um aumento significativo do IProd dos conselhos a partir do oitavo ano de idade. Isso significa que, depois desse momento, os conselhos começam a emitir atos que não dizem respeito à autorregulação e à autogestão. Quando o IProd total é desagregado pelos três tipos de conselho, aprecia-se claramente que aqueles de alta indução federal (C1) registram produtividade bem mais elevada. Assim, a distribuição do IProd total pela idade dos conselhos segue a distribuição do padrão decisório desse tipo. Mais: enquanto os conselhos $\mathrm{C} 1$ registram um IProd total ${ }^{27}$ de 2,53 (IProd médio $^{28}$ de 0,36 ), os conselhos com média e baixa indução federal acusam resultados muito inferiores: 0,48 (IProd médio de 0,12) e 0,27 (IProd médio de 0,02$)$ respectivamente. Repare-se que apenas a evolução do IProd do tipo C1 ultrapassa o valor 1 durante mais de um ano, ou seja, o 
limiar em que o conjunto de outras decisões é superior ao daquelas de autogestão.

Com o intuito de aferir não apenas a produtividade mas também a presença de padrões decisórios com maior capacidade de incidência em políticas, formulou-se um segundo índice. O Índice de Incidência em Políticas (IIP) leva em consideração apenas os atos, em princípio, mais claramente orientados para a definição e o controle de políticas, a saber, aqueles classificados nas categorias "definição geral da política" e "fiscalização da política". O IIP é a proporção de ambas sobre as demais categorias ${ }^{29}$.

O Gráfico 5, de incidência potencial em políticas, evidencia que os tipos de conselho apresentam padrões diferentes. De um lado, reitera a preponderância dos conselhos do tipo $\mathrm{C} 1$, cujas cifras conduzem o comportamento do padrão decisório agregado. De outro, mostra que os conselhos do tipo C2 apresentam desempenho notável, sendo os únicos que produziram número superior de decisões voltadas para a definição e a fiscalização de políticas do que o volume agregado dos outros tipos de ato. Esse limiar é indicado pelo número 1 no eixo dos valores do índice. Os conselhos do tipo C2 registram maior atividade decisória nos primeiros anos de seu ciclo de vida. $\mathrm{O}$ resultado decorre

\section{Gráfico 5}

Distribuição do Índice de Incidência dos Tipos de Conselho (C1, C2 e C3) pelo Ciclo de Vida Guarulhos (2005-2011)

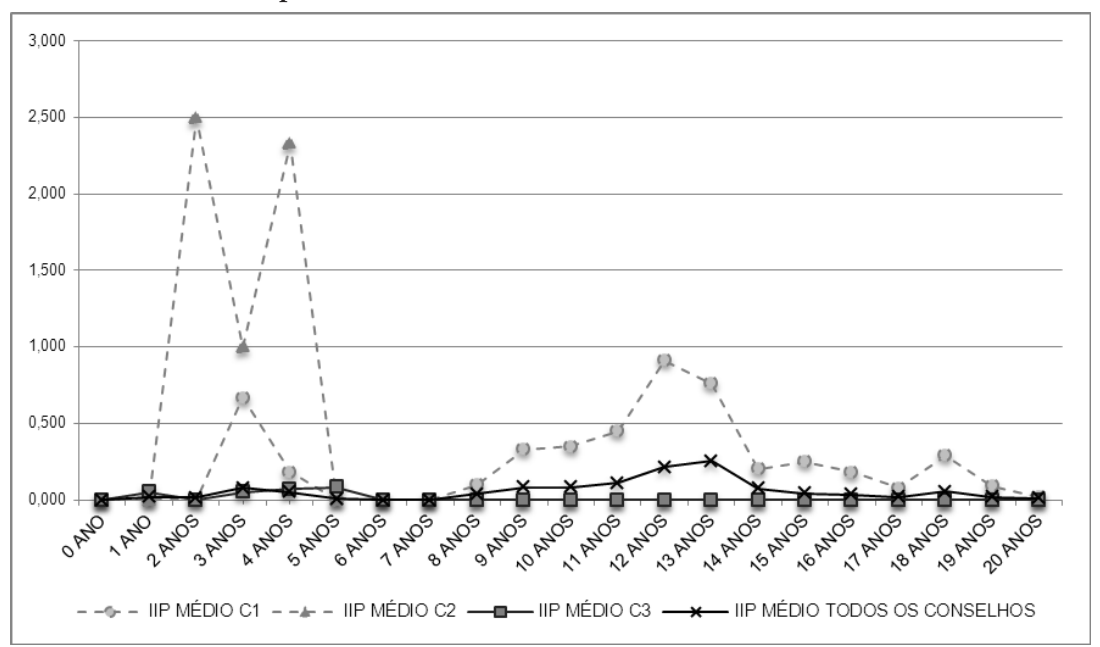

Fonte: Projeto Desigualdade Política e Representação Extraparlamentar (CEM-Cepid). 
em boa medida do padrão decisório do $\mathrm{CMH}$, criado em 2007 e, portanto, presente no banco apenas em seus quatro primeiros anos de vida. Por sua vez, o desempenho relativamente fraco dos conselhos do tipo C1 no IIP exprime a predominância de atos administrativos de gestão no caso do segundo conselho mais produtivo de Guarulhos $(\text { CMDCA })^{30}$.

\section{CONCLUSÕES}

Apresentou-se neste artigo uma exploração inicial dos padrões decisórios ao longo do ciclo de vida de todos os conselhos do município de Guarulhos, considerando a totalidade dos atos administrativos emitidos por eles entre 2005 e 2011. Trata-se de um contexto politicamente favorável à multiplicação dos conselhos e, plausivelmente, à sua operação. Contudo, a proliferação dessas instituições participativas (IPs), mesmo que sob a égide de quatro mandatos petistas consecutivos comprometidos com a ampliação da participação, não equivale a seu efetivo funcionamento. Nove dos dez conselhos que nem sequer emitiram um único ato administrativo no período estudado foram criados pela Prefeitura durante os anos do PT.

Os resultados de Guarulhos apontam de modo consistente para a presença de atividade decisória consideravelmente mais elevada nos conselhos do tipo C1 - com alta indução federal, ampla presença nos municípios do Brasil e elevado grau de integração a seus respectivos setores ou áreas de políticas. Os conselhos dos tipos C2 e C3 (especialmente os últimos) apresentam patamares de atividade decisória modestos ou francamente minúsculos. Assim, os resultados dos conselhos inativos e daqueles ativos no tipo $\mathrm{C} 3$ sugerem que as iniciativas municipais de criação de conselhos padecem de capacidade limitada para "tirá-los do papel" e torná-los atuantes.

Ademais, os padrões decisórios dos conselhos agregados (tipos C1, C2 e C3) apresentam características similares: concentração nas decisões de gestão e, em segundo lugar, nas de autorregulação e autogestão, conforme apontado pela literatura; as primeiras com peso notavelmente maior nos conselhos C1. Uma parte menor das decisões tomadas por conselhos visam a atividades com capacidade de incidência direta sobre políticas, em particular no caso desses conselhos (C1). Esse conjunto de atos administrativos tem recebido atenção limitada na literatura, plausivelmente por sua menor visibilidade. Contudo, parece 
razoável esperar que atos de definição de diretrizes gerais decorram, por sua própria natureza, de processos decisórios menos frequentes.

Os resultados também revelam que o processo de amadurecimento dos conselhos é de aproximadamente oito anos, momento que marca a diversificação dos atos administrativos emitidos, aumentando o espectro das decisões para além do escopo centrado na autorregulação e na autogestão. Mesmo assim, conselhos do tipo C1 e C2 acusam tempo de maturação mais curto, enquanto os conselhos do terceiro tipo requerem um período mais longo para produzir decisões atinentes às respectivas políticas públicas, pelo que os conselhos dos tipos $\mathrm{C} 2$ e C3 apresentam uma relação entre padrão decisório e ciclo de vida diferente. De fato, o Índice de Produtividade dos Conselhos (IProd) mostra que o peso das decisões focadas na autorregulação cede passo aos outros tipos de decisão a partir do oitavo ano de vida dos conselhos graças à evolução do padrão decisório dos conselhos $\mathrm{C} 1$. Por sua vez, o Índice de Incidência em Políticas (IIP) evidencia que apenas os conselhos dos tipos C1 e C2 apresentam padrões decisórios em que atos administrativos orientados para a definição e a fiscalização de políticas se aproximam do volume das demais decisões ou o superam, embora isso ocorra de modo mais limitado no primeiro conjunto de conselhos e em momentos distintos do ciclo de vida.

Quanto é possível generalizar os padrões decisórios encontrados para os três tipos de conselho e para conselhos específicos, cujos resultados desafiam as descrições mais usuais da literatura? A resposta é dupla e simples. Primeiro, ainda não é possível generalizar, mas as operações analíticas e as escolhas metodológicas aqui expressas propõem um caminho possível para avançar sistemática e comparativamente rumo à generalização. Levantamentos censitários ou amostrais semelhantes precisam ser realizados, e os resultados apurados e examinados. Segundo, uma modalidade negativa de generalização é possível, aquela que opera contra proposições assentes na literatura. A esse respeito as evidências aqui expostas sugerem correções.

Os padrões decisórios destoam dos diagnósticos mais pessimistas sobre a capacidade dos conselhos, mostrando que, em Guarulhos, apesar de parte expressiva dos atos emitidos estar relacionada à autorregulação, eles são dominantes apenas nos conselhos dos tipos C2 e C3. As decisões de gestão aparecem concentradas nos conselhos do tipo $\mathrm{C} 1$. Ademais, uma quantidade não desprezível dos atos administrativos 
(23\%) implica potencial de incidência direta em políticas pela via da definição de diretrizes ou da fiscalização de resultados e procedimentos. Tais decisões visam definir ou modificar a operação, o escopo e as prioridades de alocação de recursos; ou sancionam, vetam e avaliam publicamente o desempenho de órgãos públicos e de agentes executores das políticas; e mais $5 \%$ das decisões dedicam-se a coordenar e a supervisionar outras instâncias de governança participativa.

A variação dos padrões ao longo do ciclo de vida evidencia que a desproporção entre decisões destinadas à autorregulação e outros atos administrativos guarda relação estreita com a idade dos conselhos. Depois de um processo de "amadurecimento", decisões de autorregulação continuam estáveis, mas eleva-se substancialmente a emissão de atos com outros fins. Não parece descabido supor que o tempo de "maturação" deriva de os conselhos estarem dedicados a definir seu primeiro corpo de representantes, criar e promulgar seu estatuto interno, estabelecer normas de conduta para seus membros, criar rotinas etc. É possível supor ainda que os diagnósticos pessimistas que enfatizaram a produção conselhista centrada na autorregulação tenham sido vítimas não somente de escolhas metodológicas inadequadas para a verificação da variação na produção decisória dos conselhos, mas também do viés derivado do momento de observação no processo de maturação dos conselhos, animando diagnósticos precoces, porque realizados nos primeiros anos de vida deles.

As cifras avultadas de dois conselhos (CMAS e CMDCA) ou o perfil acanhado dos padrões decisórios dos conselhos da área de educação (CME, CAE e CMACS-Fundeb) corroboram a relevância das características setoriais da política, documentadas pela literatura da segunda geração. Contudo, alguns resultados surpreendem: não apenas existem conselhos do tipo C3 consideravelmente ativos (CMDPD, Comad), mas outros, inscritos em setores de políticas notoriamente mais estruturados, como saúde ou habitação, apresentam número de decisões modesto - uma média de 4 (CMH) e 10 (CMS) atos administrativos por ano no período estudado.

Os próximos passos são o desdobramento natural da análise aqui apresentada e vão rumar em três direções. Primeiro, a incorporação de novos municípios à análise, sob o mesmo tratamento censitário e tipologias aprimorados no caso de Guarulhos, permitirá testar a estabilidade dos padrões aqui explorados e introduzir ajustes pertinentes para um 
diagnóstico de maior escala. Segundo, os tipos agregados de decisões aqui examinados abarcam uma diversidade ampla de atos administrativos, cujas implicações mais precisas para as políticas apenas podem ser elucidadas mediante exame mais nuançado. Assim, o exame da variação interna dos tipos de decisões, especialmente daquelas com implicações relevantes para as interpretações comuns na literatura como aquelas dedicadas à gestão ("cartoriais") -, promete ganhos cognitivos para o campo. Por fim, a centralidade das determinações da política setorial para explicar as diferenças na capacidade dos conselhos, conforme mostrado pela literatura da segunda geração, poderá ser testada e qualificada pela comparação intrassetorial de padrões decisórios entre municípios. Sistematizar e descrever padrões decisórios permite avançar acumulativamente no conhecimento daquilo que, de fato, os conselhos fazem e quando o fazem, sedimentando terreno mais firme para o desenvolvimento da agenda sobre a efetividade das instituições participativas. Decisões, é claro, não equivalem à efetividade, conforme oportunamente advertido, mas constituem indícios relevantes por pelo menos dois motivos: a eventual incidência em políticas por parte dos conselhos supõe resoluções que visam a essa incidência, e a verificação da variação dos padrões decisórios permite qualificar os efeitos passíveis de serem esperados.

(Recebido para publicação em abril de 2015)

(Reapresentado em janeiro de 2016) (Aprovado para publicação em fevereiro de 2016) 


\section{NOTAS}

1. Balanços abrangentes da produção acadêmica sobre os conselhos gestores de políticas públicas podem ser consultados em Tatagiba (2002) e em Souza e Vasconcelos (2006), especificamente sobre educação; em Almeida, Cayres e Tatagiba (2015), a partir de pesquisa bibliométrica; e em Raichelis (1998), sobre assistência social.

2. Isso a despeito de a maior parte dos conselhos estar regulada por regras semelhantes quanto à composição interna, de índole bipartite e normalmente paritária entre conselheiros do governo e da sociedade civil.

3. Os conselhos compreendidos em cada tipo serão explicitados na seção seguinte.

4. Essa primeira geração de estudos dos anos 1990 e início da década seguinte foi objeto de exame no influente balanço de Tatagiba (2002).

5. Por exemplo, é "evidente que, apesar dos avanços obtidos, a institucionalização da participação não resultou em uma maior influência da sociedade no processo de planejamento da política" (Tatagiba 2007a:106).

6. Diga-se de passagem, não é prudente assumir que as funções ditas "cartoriais" são irrelevantes do ponto de vista da política pública e de seu controle por atores sociais.

7. Estudos de caso também podem oferecer suporte para a generalização de índole negativa quando esta descansa em raciocínios analíticos de refutação da teoria ou, com mais precisão, das proposições dela derivadas.

8. Variáveis comuns utilizadas são: existência ou não de conselhos, conselhos ativos ou inativos e número de reuniões realizadas.

9. Os dados foram obtidos mediante procura nos arquivos digitalizados dos diários oficiais pelos seguintes termos: conselho, resolução, orçamento participativo, governança participativa e participação social.

10. Os diários continham em média 40 páginas, com cerca de 3.100 caracteres cada uma.

11. Não foi limitado a priori o perfil do que poderia ser considerado "conselho". Depois do levantamento censitário, verificaram-se as características dos casos encontrados. Preservaram-se para a análise os casos que correspondem às feições normalmente associadas aos conselhos gestores de políticas (ver nota 2).

12. Conselhos criados imediatamente após a extinção de outro conselho para desempenhar as mesmas funções foram contados apenas uma vez.

13. Atos repetidos ou que corrigem atos anteriormente publicados foram registrados na base de dados, mas não foram contabilizados na análise para evitar contagem dupla. Esses atos não alteram o tipo de decisão, quer dizer, não afetam a classificação do ato inicial objeto de correção.

14. O universo exclui atos administrativos sem informação (SI) e aqueles aos quais não se aplica a classificação (NA).

15. Resultados preliminares de atividade decisória dos conselhos de Porto Alegre coincidem com o padrão encontrado em Guarulhos, igualmente, sem acusar efeitos das eleições locais.

16. A ampliação do escopo comparativo a municípios de grande e médio porte é o foco atual do projeto que originou os resultados aqui apresentados.

17. Para uma exceção, ver Arretche (2002:85-99). 
18. Ver http://www.guarulhos.sp.gov.br/index.php?option=com_content\&view = article\&id=88\&Itemid $=286$. Acessado em 5 de novembro de 2015.

19. Outros conselhos apresentam conjunto de funções mais delimitado, como ocorre claramente nos seguintes casos: CME, CAE e CMACS-Fundeb, dedicados precipuamente ao controle social das políticas de educação.

20. Os tipos 1 e 2 ordenam conforme o critério do momento da decisão (ex ante ou ex post) os atos administrativos que, mediante análise das deliberações registradas em atas, Menicucci (2010) ordena como categorias de controle.

21. O tipo inclui tanto aquilo que Cunha (2010) classifica sob as categorias "gestão" e "registro de instituições", em sua análise das atas de conselhos de cinco capitais e de cinco cidades do interior, quanto o exercício de funções denominadas "cartoriais" pela literatura.

22. O valor de $\mathrm{N}^{\prime}$ é calculado a partir da subtração do número de conselhos inativos do conjunto total de conselhos daquele tipo (N). Para conselhos tipo $\mathrm{C} 1, \mathrm{~N}=7$ e N' = 7; conselhos do tipo $\mathrm{C} 2, \mathrm{~N}=5 \mathrm{e} \mathrm{N}^{\prime}=4$; conselhos do tipo $\mathrm{C} 3, \mathrm{~N}=21 \mathrm{e} \mathrm{N}^{\prime}=12$. Nesse caso, os atos são contados para cada conselho, ou seja, atos emitidos em conjunto por dois conselhos são duplamente contados.

23. Resultados dos padrões decisórios e ciclo de vida dos conselhos de Porto Alegre revelam padrões muito similares aos encontrados em Guarulhos (Gurza Lavalle et al., 2015).

24. A unidade dos gráficos é ano-conselho. Cada conselho pode contar até sete vezes no período contemplado.

25. Os índices apresentados a seguir desconsideram atos publicados em conjunto.

26. O IProd foi calculado da seguinte forma: a somatória dos atos de Definição da Política, Fiscalização da Política, Gestão Administrativa e Regulação de IPs dividida pela somatória dos atos de Autorregulação e Autogestão.

27. O IProd total por tipo de conselho compreende todos os atos emitidos por tipo.

28. O IProd médio por tipo de conselho controla o número de conselhos ativos existentes em cada conjunto de conselhos. Os respectivos valores são: 7 conselhos do tipo C1; 4 conselhos do tipo C2; e 12 conselhos do tipo C3.

29. O IIP foi calculado da seguinte forma: a somatória dos atos de definição da política e fiscalização da política dividida pela somatória dos demais atos.

30. A distribuição entre atos de "definição geral da política" (1) e de "gestão administrativa" (3) é bastante uniforme no CMAS, o conselho com a maior produção do município. 


\section{REFERÊNCIAS BIBLIOGRÁFICAS}

ALMEIDA, Carla. (2009), "Conselhos Gestores e Regulação: A Assistência Social em Tempos de Transição". Política \& Sociedade, vol. 8, no 15, pp. 251-269.

; TATAGIBA, Luciana. (2012), “Os Conselhos Gestores sob o Crivo da Política: Balanços e Perspectivas". Serviço Social \& Sociedade, no 109, pp. 68-92.

ALMEIDA, Carla; CAYRES, Domitila Costa; TATAGIBA, Luciana. (2015), "Balanço dos Estudos sobre os Conselhos de Políticas Públicas na Última Década”. Lua Nova, no 94, pp. 255-294.

ARRETCHE, Marta (coord.). (2002), Capacidades Administrativas dos Municípios Brasileiros para a Política Habitacional. São Paulo, CEM/Ministério das Cidades.

AVRITZER, Leonardo. (2008), Instituições Participativas e Desenho Institucional: Algumas Considerações sobre a Variação da Participação no Brasil Democrático. Opinião Pública, vol. 14, no 1, pp. 43-64.

. (2009), Participatory Institutions in Democratic Brazil. Washington, DC, Woodrow Wilson Press.

(2010), "Introdução", in L. Avritzer (org.), A Dinâmica da Participação Local no Brasil. São Paulo, Cortez, pp. 7-56.

et al. (2005), Relatório de Pesquisa. Reinventando os Mecanismos de Inclusão e Controle Social nos Conselhos de Saúde. Belo Horizonte, Fapemig.

BENEVIDES, Maria Victoria de Mesquita. (1994), "Citizenship and Democracy". Lua Nova, no 33, pp. 5-16.

BRASIL, Flávia de Paula Duque et al. (2013), "Participação, Desenho Institucional e Alcances Democráticos: Uma Análise do Conselho das Cidades (ConCidades)". Revista de Sociologia e Política, vol. 21, no 48, pp. 5-18.

CARNEIRO, Carla Bronzo Ladeira. (2002), “Conselhos de Políticas Públicas: Desafios para sua Institucionalização". Revista de Administração Pública, vol. 36, no 2, pp. 277-292.

CORTES, Soraya Vargas. (2002a), "Participação de Usuários nos Conselhos Municipais de Saúde e de Assistência Social de Porto Alegre", in R. Perissinotto e M. Fuks (orgs.), Democracia: Teoria e Prática. Rio de Janeiro, Relume Dumará, pp. 167-209.

. (2002b), "Construindo a Possibilidade da Participação dos Usuários: Conselhos e Conferências no Sistema Único de Saúde". Revista Sociologias, ano 4, no 7, pp. 18-49.

(2009), "Sistema Único de Saúde: Espaços Decisórios e a Arena Política de Saúde". Cadernos de Saúde Pública, vol. 25, no 7, pp. 1626-1633.

. (2011), “As Diferentes Instituições Participativas Existentes nos Municípios Brasileiros", in R. R. Pires (org.), Efetividade das Instituições Participativas no Brasil: Estratégias de Avaliação. Brasília, Ipea, pp. 137-149, vol. 7.

CUNHA, Eleonora Schettini Martins. (2007), “A Efetividade Deliberativa dos Conselhos Municipais de Saúde e de Criança e Adolescente no Nordeste”, in L. Avritzer (org.), Participação Social no Nordeste. Belo Horizonte, Editora UFMG. 
. (2009), Efetividade Deliberativa: Estudo Comparado de Conselhos Municipais de Assistência Social (1997-2006). Tese (Doutorado em Ciência Política), Faculdade de Filosofia e Ciências Humanas, Universidade Federal de Minas Gerais (UFMG), Belo Horizonte.

. (2010), "Inclusão Social e Política: O Desafio Deliberativo dos Conselhos Municipais de Assistência Social", in L. Avritzer (org.), A Dinâmica da Participação Local no Brasil. São Paulo, Cortez, pp. 93-128, vol. 1.

CYMBALISTA, Renato; MOREIRA, Tomás. (2002), “O Conselho Municipal de Habitação em São Paulo". Observatório dos Direitos do Cidadão. São Paulo, Instituto Pólis/PUC-SP.

FEDOZZI, Luciano; LIMA, Kátia. (2013), “Os Orçamentos Participativos no Brasil”, in N. Dias (org.), Esperança Democrática: 25 Anos de Orçamentos Participativos no Mundo. Portugal, In Loco, pp. 151-162, vol. 1.

FUKS, Mário; PERISSINOTTO, Renato Monseff; SOUZA, Nelson Rosário (orgs.). (2004), Democracia e Participação: Os Conselhos Gestores do Paraná. Curitiba, UFPR.

GOHN, Maria da Glória. (2004), “Movimentos Sociais: Espaços de Educação Não Formal da Sociedade Civil". Nuevamerica, vol. 3, no 3, pp. 11-20.

GURZA LAVALLE, Adrian. (2011a), "Após a Participação: Nota Introdutória”. Lua Nova, no 84, pp. 13-23.

. (2011b), “Participação: Valor, Utilidade, Efeitos e Causa”, in R. R. Pires (org.), Efetividade das Instituições Participativas no Brasil: Estratégias de Avaliação. Brasília, Ipea, pp. 33-42, vol. 7.

; BARONE, Leonardo Sangali. (2015), "Conselhos, Associações e Desigualdade", in M. Arretche (org.), Trajetórias das Desigualdades: Como o Brasil Mudou nos Últimos Cinquenta Anos? São Paulo, Unesp/CEM.

GURZA LAVALLE, Adrian; ISUNZA VERA, Ernesto. (2011), “A Trama da Crítica Democrática: Da Participação à Representação e à Accountability". Lua Nova, no 84, pp. 353-364.

GURZA LAVALLE, Adrian; SERAFIM, Lizandra; OLIVEIRA, Osmany Porto de. (2011), "What Makes Participatory Experiences Successful?". Chance 2 Sustain Policy Brief Series. União Europeia, o 4 .

GURZA LAVALLE, Adrian et al. (2011), “Guarulhos as Best Case: Mapping Participatory Governance Structure and Social Conflicts". (Relatório de Pesquisa Chance 2 Sustain Project.)

GURZA LAVALLE, Adrian et al. (2015). “'Political Inequality and Extra-Parliamentary Representation' - Alguns Resultados Comparativos; Aspectos Metodológicos e Caminhos Futuros". Relatório de Pesquisa apresentado no Seminário Conjunto Cepid-CEM, realizado em 9 e 10 de março.

IBGE (Instituto Brasileiro de Geografia e Estatística). (2012), “Produto Interno Bruto dos Municípios Brasileiros". Contas Nacionais, Rio de Janeiro, no 43, Tabela 1.

IBGE-Munic. (2009), "Pesquisa de Informações Básicas Municipais". Rio de Janeiro, IBGE.

DADOS - Revista de Ciências Sociais, Rio de Janeiro, vol. 59, nº 3, 2016 
KAYANO, Jorge et al. (2007), “Governança e Regulação na Saúde: Desafios para a Gestão na Região Metropolitana de São Paulo, Brasil”. Cadernos de Saúde Pública, vol. 23, no 3, pp. 575-584.

KING, Gary; KEOHANE, Robert O.; VERBA, Sidney. (1994), Designing Social Inquiry: Scientific Inference in Qualitative Research. Princeton, NJ, Princeton University Press.

LEANDRO SILVA, Expedito (coord.), (1998), Formação de uma Metrópole: Guarulhos. Guarulhos, $\mathrm{CDDH}$.

MENICUCCI, Telma Maria Gonçalves. (2010), “A Política para Crianças e Adolescentes em Capitais Brasileiras: Os Conselhos Importam?", in L. Avritzer (org.), A Dinâmica da Participação Local no Brasil. São Paulo, Cortez, pp. 175-214, vol. 3.

PAZ, Rosângela Dias Oliveira da (org.). (2001), Política de Assistência Social: Uma Trajetória de Avanços e Desafios. São Paulo, Abong, 2001, vol. 30.

PIETÁ, Elói. (1992). Revirando a História de Guarulhos. São Paulo, Cajá.

PIRES, Roberto Rocha. (2010), Flexibilidade, Consistência e Impactos na Gestão do Desempenho Burocrático: Subsídios para uma Nova Sistemática de Acompanhamento e Avaliação do Desempenho da Inspeção do Trabalho no Brasil. Brasília, OIT.

(org.). (2011), Efetividade das Instituições Participativas no Brasil: Estratégias de Avaliação. Brasília, Ipea.

PIRES, Roberto Rocha; TOMÁS, Maria C. (2007), “Instituições Participativas e Gestão Municipal no Nordeste: Uma Análise dos Efeitos da Participação sobre as Práticas de Governo", in L. Avritzer (org.), A Participação Social no Nordeste. Belo Horizonte, Editora UFMG, pp. 163-189.

PIRES, Roberto Rocha; LOPEZ, Felix Garcia. (2010), “Instituições Participativas e Políticas Públicas no Brasil: Características e Evolução nas Últimas Duas Décadas", in Instituto de Pesquisa Econômica Aplicada (org.), Brasil em Desenvolvimento: Estado, Planejamento e Políticas Públicas. Brasília, Ipea, pp. 565-588, vol. 3.

PIRES, Roberto Rocha; VAZ, Alexander Cambraia. (2010a), “A Efetividade das Instituições Participativas no Brasil: Perspectivas, Estratégias Metodológicas e Resultados". Texto base para oficina. Brasília, Ipea.

. (2010b), “Participação Faz Diferença? Uma Avaliação das Características e Efeitos da Institucionalização da Participação nos Municípios Brasileiros", in L. Avritzer (org.), A Dinâmica da Participação Local no Brasil. São Paulo, Cortez, pp. 222-265, vol. 1.

RAICHELIS, Raquel. (1998), Esfera Pública e Conselhos de Assistência Social: Caminhos da Construção Democrática. São Paulo, Cortez.

. (2003), "A Relação entre os Conselhos e os Movimentos Sociais". Cadernos Pólis, no 12.

RANALI, João. (2002), Repaginando a História. São Paulo, Soge.

SANTOS JUNIOR, Orlando Alves dos; MONTANDON, Daniel Todtmann (orgs.). (2011), Os Planos Diretores Municipais Pós-Estatuto da Cidade: Balanço Crítico e Perspectivas. Rio de Janeiro, Letra Capital/Observatório das Cidades/Ippur/UFRJ.

SOUTO, Anna Luiza Salles; PAZ, Rosangela (orgs.). (2003), Articulação entre os Conselhos Municipais. São Paulo, Instituto Pólis, vol. 12. 
SOUZA, Clóvis et al. (2013), “Ampliação da Participação na Gestão Pública: Um Estudo sobre Conferências Nacionais Realizadas entre 2003 e 2011". Relatório de Pesquisa, Ipea.

SOUZA, Donaldo Bello de; VASCONCELOS, Maria Celi Chaves. (2006), “Os Conselhos Municipais de Educação no Brasil: Um Balanço das Bibliografias Nacionais (1996-2002)". Ensaio: Avaliação e Políticas Públicas em Educação, vol. 14, no50, pp. 39-56.

TATAGIBA, Luciana. (2002), “Os Conselhos Gestores e a Democratização das Políticas Públicas no Brasil", in E. Dagnino (org.), Sociedade Civil e Espaços Públicos no Brasil. São Paulo, Paz e Terra/Unicamp, pp. 47-105.

. (2005), "Conselhos Gestores de Políticas Públicas e Democracia Participativa: Aprofundando o Debate". Revista de Sociologia e Política, vol. 25, pp. 247-250.

. (2007a), “O Papel do COMAS na Política de Assistência Social em São Paulo”, in C. C. Arregui et al. Assistência Social: Controle Social e Política Pública. São Paulo, Instituto Pólis/PUC-SP, pp. 49-115. (Série Observatório dos Direitos do Cidadão, no 30).

. (2007b), “O Papel do CMDCA na Política de Atendimento à Criança e ao Adolescente em São Paulo", in A. dos Santos; L. Tatagiba, Criança e Adolescente: Controle Social e Política Pública. São Paulo, Instituto Pólis / PUC-SP, pp. 7-77. (Série Observatório dos Direitos do Cidadão, no 28).

; TEIXEIRA, Ana Claudia Chaves. (2007a), “O Papel do CMH na Política de Habitação em São Paulo", in R. Cymbalista et al., Habitação: Controle Social e Política Pública. São Paulo, Instituto Pólis/PUC-SP, pp. 61-114. (Série Observatório dos Direitos do Cidadão, no 31).

. (2007b), “O Papel do CMS na Política de Saúde em São Paulo”, in J. Kayano, L. Tatagiba; A. C. C. Teixeira, Saúde: Controle Social e Política Pública. São Paulo, Instituto Pólis/PUC-SP, pp. 59-117. (Série Observatório dos Direitos do Cidadão, no 29).

TEIXEIRA, Ana Claudia Chaves. (2014), Estudo sobre Sistemas Nacionais de Políticas Públicas. Brasília, PNUD e Secretaria Geral da Presidência da República.

; TATAGIBA, Luciana. (2008), “Movimientos Sociales y Sistema Político: Los Desafíos de la Participación”, in A. C. C. Teixeira (org.), Desafíos de la Construcción Democrática en Brasil: Participación. São Paulo, Instituto Pólis, pp. 13-104.

TELLES, Vera da Silva. (1994), “Sociedade Civil, Direitos e Espaços Públicos". Pólis, no 14, pp. 43-54.

VAZ, Alexander Cambraia; PIRES, Roberto Rocha C. (2011), “Comparações entre Municípios: Avaliação dos Efeitos da Participação por meio de Pares Contrafactuais", in R. R. C. Pires (org.), Efetividade das Instituições Participativas no Brasil: Estratégias de Avaliação. Brasília, Ipea, pp. 247-262, vol. 7. 


\section{RESUMO}

\section{O que Fazem os Conselhos e Quando o Fazem? Padrões Decisórios e Efeitos das Instituições Participativas}

O artigo explora levantamento da produção decisória dos conselhos gestores de políticas públicas visando compreender o que fazem e quando o fazem, isto é, em que momento de seu ciclo de vida. É consenso na literatura o fato de a ampla expansão e institucionalização de instâncias de participação demandar diagnósticos sobre sua efetividade. A agenda da efetividade das instituições participativas tem contribuído a avançar na aferição de efeitos sobre o desempenho de políticas. Objetivamos contribuir ao debate adotando uma estratégia analítica diferente: focar a produção decisória dos conselhos (outputs) e não seus efeitos sobre as políticas (outcomes). Os resultados sugerem correções a diagnósticos amplamente aceitos na literatura. A análise apresentada é inovadora em três sentidos: i) parte-se de um diagnóstico da evolução territorial dos conselhos municipais no país que oferece base empírica robusta para uma tipologia de conselhos; ii) depois, examinam-se os padrões decisórios de 32 conselhos mediante levantamento censitário de todas as decisões produzidas pelos mesmos durante 7 anos (2005-2011) no município de Guarulhos - caso emblemático pelas condições favoráveis à implementação de instituições participativas, especialmente nas últimas quatro gestões do PT; e iii) propõe-se métricas de produção e incidência potencial em políticas para avaliar os padrões decisórios dos conselhos.

Palavras-chave: instituições participativas; efetividade; produção decisória; conselhos gestores; participação

\section{ABSTRACT \\ What do Councils do and When? Decision-making Standards for Participatory Institutions and their Effects}

This article explores a survey on decisions taken by public policies management councils, in order to find out what they do and when they do it in terms of their life cycle. There is a consensus in literature the ziseable expansion and institutionalization of participatory bodies have led to the need for diagnoses of their effectiveness. Participatory institutions' effectiveness agendas have contributed to advancements made in the assessment of effects on policy performance. Our aim is to contribute to the debate by adopting a different analytical strategy: focusing on the decisions taken by the councils (outputs) rather than on their effects on policies (outcomes). The findings suggest corrections to diagnoses widely accepted in literature. This approach is innovative in three senses: i) it is based on a diagnosis of the territorial evolution of municipal councils in Brazil that provides a robust empirical basis for a typology of the councils; ii) it goes on to examine the decision-making 
patterns for 32 councils by means of a census of decisions, that is by analysing data collected for all of the decisions made by the councils over a 7-year period (2005-2011) in the municipality of Guarulhos - an emblematic case due to the favorable conditions for implementing participatory institutions, especially during the Workers' Party's (PT) last four terms in office; and iii) it proposes metrics on outputs and potential policy impacts assess the councils' decision-making patterns.

Key words: participatory institutions; effectiveness; outputs; management councils; participation

\section{RÉSUMÉ \\ Que Font les Conseils et Quand le Font-ils? Modèles Décisionnaires et Effets des Institutions Participatives}

Cet article explore types de décision prise aux Conseils de gestion des politiques publiques dans le but de comprendre ce qu'ils font et quand ils le font, à savoir à quel moment de leur cycle de vie. Il existe un consensus dans la littérature pour dire que l'expansion et l'institutionnalisation des instances de participation sociale doivent faire l'objet de diagnostics quant à leurs efficacité. Le débat sur l'efficacité de ces institutions participatives a permis d'avancer dans l'analyse de leurs effets sur les performances des politiques en question. Nous souhaitons contribuer au débat en adoptant une stratégie analytique différente, c'est-à-dire en nous concentrant sur les décisions effectivement prises par lesdits conseils (outputs) et non sur leurs effets sur les politiques (outcomes). Les résultats suggèrent d'apporter des corrections aux diagnostics les mieux acceptés de la littérature du domaine, et ce grâce à une analyse innovante sous trois points de vue: i) on part d'un diagnostic de l'évolution territoriale des conseils communaux pour offrir une base empirique robuste à la création d'une typologie; ii) on examine ensuite les modèles décisionnaires de 32 conseils moyennant un inventaire de l'ensemble des décisions produites par ceux-ci pendant 7 ans (2005-2011) dans la commune de Guarulhos - un cas emblématique en raison des conditions favorables à la mise en œuvre d'institutions participatives, principalement lors des quatre derniers mandats du PT; et iii) on propose enfin des mécanismes d'analyse de leur production et de leur incidence potentielle sur les politiques pour évaluer les modèles décisionnaires des conseils.

Mots-clés: institutions participatives; effectivité; prise de décisions; conseils de gestion; participation 


\section{RESUMEN \\ ¿Qué Hacen los Consejos y cuándo lo Hacen? Patrones Decisorios y Efectos de las Instituciones Participativas}

El artículo explora el inventario de la producción decisoria de los consejos gestores de políticas públicas con el fin de comprender lo que hacen y cuando lo hacen, es decir, en qué momento de su ciclo de vida. Es un consenso en la literatura que la amplia expansión e institucionalización de instancias de participación demanda diagnósticos sobre su efectividad. La agenda de la efectividad de las instituciones participativas ha contribuido a avanzar en la evaluación de sus efectos sobre el desempeño de políticas. Buscamos contribuir al debate adoptando una estrategia analítica diferente: nos concentramos en la producción decisoria de los consejos (outputs) y no en sus efectos sobre las políticas (outcomes). Los resultados sugieren correcciones de diagnósticos ampliamente aceptados en la literatura. El análisis de ese inventario innovador en tres sentidos: i) se parte de un diagnóstico de la evolución territorial de los consejos municipales en el país que ofrece una base empírica robusta para una tipología de consejos; ii) luego, se examinan los padrones decisorios de 32 consejos mediante el inventario censitario de todas las decisiones producidas por los mismos durante 7 años (2005-2011) en el municipio de Guarulhos - caso emblemático por las condiciones favorables a la implementación de instituciones participativas, especialmente en las últimas cuatro gestiones del PT; iii) se proponen medidas de productividad e incidencia potencial en políticas para evaluar los padrones decisorios de los consejos.

Palabras clave: instituciones participativas; eficacia; producción decisoria; consejos gestores; participación 